\title{
LISA: a lightweight stratospheric air sampler
}

\author{
Joram J. D. Hooghiem ${ }^{1}$, Marcel de Vries ${ }^{1}$, Henk A. Been ${ }^{1}$, Pauli Heikkinen ${ }^{2}$, Rigel Kivi ${ }^{2}$, and Huilin Chen ${ }^{1}$ \\ ${ }^{1}$ Center for Isotope Research (CIO), Energy and Sustainability Institute Groningen (ESRIG), University of Groningen, \\ Nijenborgh 6,9747 AG Groningen, the Netherlands \\ ${ }^{2}$ Finnish Meteorological Institute (FMI), Earth Observation Research, Tähteläntie 62, 99600 Sodankylä, Finland
}

Correspondence: Huilin Chen (huilin.chen@ rug.nl)

Received: 19 January 2018 - Discussion started: 26 January 2018

Revised: 17 October 2018 - Accepted: 6 November 2018 - Published: 20 December 2018

\begin{abstract}
We developed a new lightweight stratospheric air sampler (LISA). The LISA sampler is designed to collect four bag samples in the stratosphere during a balloon flight for $\mathrm{CO}_{2}, \mathrm{CH}_{4}$ and $\mathrm{CO}$ mole fraction measurements. It consists of four multi-layer foil (MLF) sampling bags, a custommade manifold, and a diaphragm pump, with a total weight of $\sim 2.5 \mathrm{~kg}$.

A series of laboratory storage tests were performed to assess the stability of $\mathrm{CO}_{2}, \mathrm{CH}_{4}$ and $\mathrm{CO}$ mole fractions in both MLF and Tedlar bags. The MLF bag was chosen due to its better overall performance than the Tedlar bag for the three species $\mathrm{CO}_{2}, \mathrm{CH}_{4}$ and $\mathrm{CO}$. Furthermore, we evaluated the performance of the pump under low pressure conditions to optimize a trade-off between the vertical resolution and the sample size.

The LISA sampler was flown on the same balloon flight with an AirCore in Sodankylä, Finland $\left(67.368^{\circ} \mathrm{N}\right.$, $26.633^{\circ}$ E, 179 ma.s.l.), on 26 April and 4-7 September 2017. A total of 15 stratospheric air samples were obtained during the ascent of four flights. The sample size ranges between 800 and $180 \mathrm{~mL}$ for the altitude between 12 and $25 \mathrm{~km}$, with the corresponding vertical resolution ranging from 0.5 to $1.5 \mathrm{~km}$. The collected air samples were analysed for $\mathrm{CO}_{2}, \mathrm{CH}_{4}$ and $\mathrm{CO}$ mole fractions, and evaluated against AirCore retrieved profiles, showing mean differences of $0.84 \mathrm{ppm}$ for $\mathrm{CO}_{2}, 1.8 \mathrm{ppb}$ for $\mathrm{CH}_{4}$ and $6.3 \mathrm{ppb}$ for $\mathrm{CO}$, respectively.

High-accuracy stratospheric measurements of greenhouse gas mole fractions are useful to validate remote sensing measurements from ground and from space, which has been performed primarily by comparison with collocated aircraft measurements $(0.15-13 \mathrm{~km})$, and more recently with AirCore observations $(0-30 \mathrm{~km})$. While AirCore is capable of
\end{abstract}

achieving high-accuracy greenhouse gas mole fraction measurements, it is challenging to obtain accurate altitude registration for AirCore measurements. The LISA sampler provides a viable low-cost tool for retrieving stratospheric air samples for greenhouse gas measurements that is complementary to AirCore. Furthermore, the LISA sampler is advantageous in both the vertical resolution and sample size for performing routine stratospheric measurements of the isotopic composition of trace gases.

\section{Introduction}

The stratosphere plays an important role in the climate of the earth and is affected by ongoing climate change. Changes in stratospheric ozone and water vapour levels in turn affect climate and climate variability (Baldwin et al., 2007). The distribution of trace gases in the atmosphere provides useful insights in atmospheric transport and chemistry. Stratospheric tracer observations are essential for validation of general circulation models (GCMs). The stratospheric meridional overturning, or the Brewer-Dobson circulation (BDC), was predicted to increase in strength from modelling studies (Butchart, 2014). The mean age of stratospheric air samples was shown to be a good diagnostic for the strength of the BDC; however, no significant change in the strength of the BDC in the Northern Hemisphere at mid-latitudes was detected (Engel et al., 2009, 2017). In spite of all the efforts to make observations of stratospheric tracers, GCMs remain poorly constrained (Gerber et al., 2012), a problem already pointed out several decades ago (Ehhalt et al., 1983).

In order to determine the vertical distribution of trace gases, both remote sensing techniques and airborne platforms 
are utilized. Remote sensing is performed either from the ground, e.g. TCCON (Wunch et al., 2011), or from satellite instruments like SCIAMACHY (Frankenberg et al., 2011) and IASI (Crevoisier et al., 2013). Although remote sensing techniques have a high spatial and temporal coverage, they are subjected to systematic bias and need to be calibrated. Calibration requires in situ measurements, of which the availability relies on infrequent campaigns (e.g. Engel et al., 2016).

In situ measurements of stratospheric air up to $35 \mathrm{~km}$ above mean sea level (a.m.s.l.) can currently only be achieved on balloon-borne platforms. To this end, both airborne analysers (e.g. Daube et al., 2002) as well as sampling techniques have been developed specifically for balloonborne platforms. Of these techniques, the cryogenic sampling method (Lueb et al., 1975) is the most employed technique. It has been used for the analysis of many trace gases like $\mathrm{SF}_{6}, \mathrm{CO}_{2}, \mathrm{CH}_{4}, \mathrm{~N}_{2} \mathrm{O}$ and halocarbons (Aoki et al., 2003; Engel et al., 2002; Laube et al., 2010; Nakazawa et al., 1995, 2002) and isotopic composition measurements (Kaiser et al., 2006; Rice et al., 2003; Röckmann et al., 2011; Sugawara et al., 1997). As outlined in Fabian (1981), cryogenic sampling overcomes the problem of small samples that are obtained from the grab sampling technique. Typically, cryogenic samplers retrieve $\sim 15$ samples of 10 to $20 \mathrm{~L}$ at STP (standard temperature and pressure) (Fabian, 1981; Honda, 2004; Lueb et al., 1975) with a sufficiently good vertical resolution of $\sim 1 \mathrm{~km}$ (Schmidt et al., 1987). This makes the cryogenic sampling technique suitable for multi-tracer and isotopic composition analysis. Secondly, the cryogenic technique provides a way of contamination-free sampling.

Inasmuch as their accuracy, these samplers and airborne analysers are heavyweight $(100-250 \mathrm{~kg})$, which requires sophisticated planning and significant resources for a single launch. As a result of the intensive operation, stratospheric observations have been sparsely made both in time and space. Existing sampling is mainly restricted to the Northern Hemisphere mid-latitudes and polar regions, with the tropics under-sampled. Recently, a light cryogenic sampler $(22 \mathrm{~kg})$ using liquid neon (Morimoto et al., 2009) was developed, and launched from a research vessel to retrieve stratospheric air samples in the tropics (Fuke et al., 2014); however, it is capable of retrieving only one sample per flight.

Recently, AirCore has been shown to be a viable method for profile measurements of greenhouse gases (GHGs)(Engel et al., 2017; Karion et al., 2010 and Membrive et al., 2017). AirCore is much lighter $(2-9 \mathrm{~kg})$ compared to the cryogenic sampler and can be launched on weather balloons. The launch of AirCore is also much simpler than the operation of large-payload cryogenic samplers. Being a passive sampling technique, AirCore does not provide a large sample amount from the stratosphere. The volume of air sampled between 0 and $200 \mathrm{hPa}$ (12 to $30 \mathrm{~km}$ ) by the AirCore ranges from 300 to $600 \mathrm{~mL}$, depending on the geometry of the AirCore. This is problematic for accurate analysis of isotopic compositions or multiple tracers. Sub-sampling of the stratospheric part of the AirCore samples has been used for measurements of $\Delta^{17} \mathrm{O}$ in $\mathrm{CO}_{2}$ (Mrozek et al., 2016) and radiocarbon analysis (Paul et al., 2016). The samples have small sample size, which limits the analytical precision of their analyses. Besides this, the vertical resolution of the samples was low and the altitude registration of these samples was associated with significant uncertainties.

In this work, we present the deployment and field tests of a new lightweight stratospheric air sampler (LISA). With the LISA sampler, we aim to develop a sampling technique complementary to AirCore. With LISA we aim for a reasonable accuracy of GHG measurements, which does not necessarily meet the World Meterological Organization (WMO)recommended compatibility goals of $0.1 \mathrm{ppm}\left(\mu \mathrm{mol} \mathrm{mol}^{-1}\right)$, $2 \mathrm{ppb}\left(\mathrm{nmol} \mathrm{mol}{ }^{-1}\right)$, and $2 \mathrm{ppb}$ for $\mathrm{CO}_{2}, \mathrm{CH}_{4}$ and $\mathrm{CO}$, respectively, but would be sufficient, e.g. to detect the large vertical gradient of $\mathrm{CH}_{4}$ in the stratosphere. Moreover, we intend to obtain significantly larger amount of air samples from the LISA sampler than from the AirCore sub-sampler.

The design of the LISA sampler is described in Sect. 2. The accuracy of the $\mathrm{CO}_{2}, \mathrm{CH}_{4}$ and $\mathrm{CO}$ mole fraction measurements of the LISA samples is assessed by the sample storage test that is detailed in Sect. 3. The vertical resolution and sample amount are both a function of sampling time and are therefore discussed together in Sect. 4. Following the development of the sampler, we present the deployment of the sampler in the field and the comparison of the $\mathrm{CO}_{2}, \mathrm{CH}_{4}$ and $\mathrm{CO}$ mole fraction measurements between the LISA sampler and AirCore in Sect. 5. Finally, we give the discussion and conclusions in Sects. 6 and 7.

\section{LISA sampler design and operation}

We designed the sampler to collect stratospheric air samples during a weather-balloon flight, where the balloon typically bursts at $\sim 30 \mathrm{~km}$ altitude. The weight of the total payload of a weather balloon typically ranges between 0.2 and $12 \mathrm{~kg}$. Therefore, the sampler needs to be lightweight. To achieve this, we have used bags to contain air samples instead of glass or metal flasks that are commonly used for accurate trace gas measurements, and a diaphragm pump instead of the previously used cryogenic coolers to pump air. Besides these, a data logger is used to make the system fully automatic during flight. The payload is housed in a Styrofoam package for thermal insulation and to prevent it from damage during landing. Previously the use of a gas pump and Tedlar bags have been successfully used to sample air from a UAV for methane studies (Greatwood et al., 2017).

Figure 1 shows the schematic diagram of the sampler. The system consists of a diaphragm pump (KNF, product no. NMP 850.1.2 KNDC B) and four Supel inert multilayer foil (MLF) bags (Supelco, product no. 30227-U). The pump has a flow capacity of $8 \mathrm{~L} \mathrm{~min}^{-1}$ at STP. The pump 


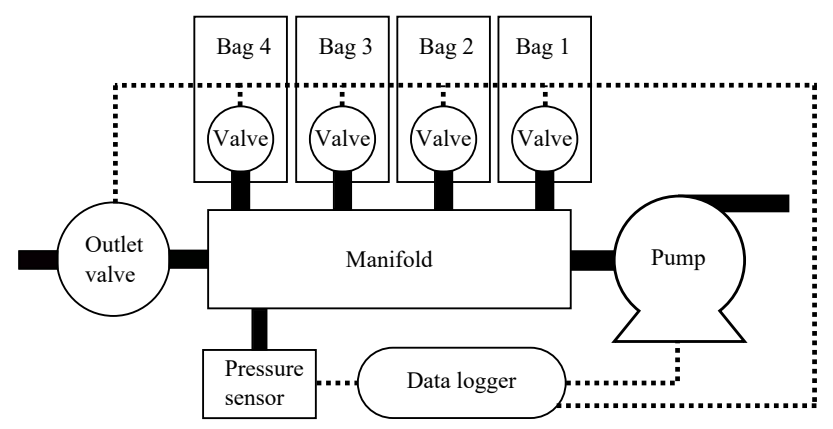

Figure 1. A schematic diagram of the sampler. Four bags are connected to a custom-made manifold. A small servomotor operates the screw cap combo valve. The outlet valve is the same as that of the bags, but is normally open when the sampler is idle during flight, allowing air pressure to equilibrate with outside air. Pressure inside the manifold is monitored by a pressure sensor. A data logger is used to control all of the electronics. Electric connections are shown with dashed lines.

utilizes an EPDM rubber diaphragm $(35 \mathrm{~mm}$ diameter) and valves, and a small piece of flexible polyurethane tube. Each bag is equipped with a screw cap combo valve that requires a $180^{\circ}$ turn to be opened or closed. A servomotor (Hitec, product no. HS-65HB+) operates the valve. The pump and bags are connected to a custom-made manifold, which is made from five nylon tees (Swagelok, product no. NY-4003 ) and five union elbows (Swagelok, product no. NY-400-9), connected by Kynar tubing (Cole Palmer, product no. EW95100-02). A fifth screw cap combo valve is placed at the outflow end as the outlet valve, allowing the manifold to be flushed prior to sampling. The pressure inside the manifold is continuously monitored by a pressure sensor (Honeywell HSCMAND015PASA5). A data logger (Arduino Mega 2560) operates all the electronics during flight, and logs ambient atmospheric pressure and temperature data, as well as the pressure inside the manifold and temperature within the Styrofoam package. The pump requires $24 \mathrm{~V}$ during operation. The power is therefore supplied by eight $3 \mathrm{~V}$ lithium ion batteries (CR123A) connected in series. The Arduino is powered by three batteries out of the eight $(9 \mathrm{~V})$. The servo motors are powered with two separate batteries $(6 \mathrm{~V})$. The sampler is placed in a Styrofoam package, with a total weight of $\sim 1 \mathrm{~kg}$ excluding the package, and $\sim 2.5 \mathrm{~kg}$ including the package. The key components are summarized in Table 1 .

Because the ascent rate is usually much slower than the descent rate, we take air samples during ascent to optimize the vertical resolution (see Sect. 4). The sampling process is triggered by starting the pump when the sampler reaches preset ambient pressure levels monitored by the on-board pressure sensor. In practice, when the preset pressure value is reached during ascent, the pump is started, with the outlet valve open and the other valves upstream of the bags closed, to flush the manifold. After $20 \mathrm{~s}$, the outlet valve is closed, and the valve upstream of one of the chosen bags is simultaneously opened to allow sampling. The sampling of air into one bag is completed when a preset maximum sampling time is exceeded or the absolute pressure in the manifold is higher than $280 \mathrm{hPa}$ (see Sect. 4), whichever comes first. The sampling process continues until all four bags are filled. At a certain altitude, the balloon will burst and the sampler falls back to the ground where the samples can be picked up and brought back to the laboratory for analysis.

\section{Sample storage tests}

The stability of trace gases in the sample container is essential for a sampler to obtain accurate measurements of the trace gases. To this end, we have investigated the stability of $\mathrm{CO}_{2}, \mathrm{CH}_{4}, \mathrm{CO}$ and $\mathrm{H}_{2} \mathrm{O}$ mole fractions of dry air samples in two types of gas sampling bags: Tedlar and Supel inert multi-layer foil (MLF). The Tedlar bag is composed of a thin polyvinyl fluoride film. The MLF bag consists of several layers: polyethylene (inner layer), aluminium foil, polyethylene, aluminium (metalized) and 60-gauge nylon, which provide a moisture barrier and light protection.

\subsection{Experiments}

A total of seven MLF and seven Tedlar bags were prepared, with dry air $\left(<0.003 \% \mathrm{H}_{2} \mathrm{O}\right)$ from a cylinder; the mole fractions of $\mathrm{CO}_{2}, \mathrm{CH}_{4}$ and $\mathrm{CO}$ are listed in Table 2. Since the mole fractions of methane are significantly lower in the stratosphere than a typical value of around $2000 \mathrm{ppb}$ in the free troposphere (e.g. Rice et al., 2003; Röckmann et al., 2011), we prepared two samples (nos. 6 and 7) with low mole fractions $\left(\sim 120 \mathrm{ppm} \mathrm{CO}_{2}, \sim 600 \mathrm{ppb} \mathrm{CH}_{4}\right.$ and $\sim 75 \mathrm{ppb}$ $\mathrm{CO}$ ) by diluting air from a cylinder with $\mathrm{N}_{2}$. The $\mathrm{CO}$ mole fractions in the stratosphere are also low, but we did not make any storage test for samples with a mole fraction lower than $\sim 75 \mathrm{ppb}$.

Directly after sample preparation, the air sample is analysed for $\mathrm{CO}_{2}, \mathrm{CH}_{4}, \mathrm{CO}$ and $\mathrm{H}_{2} \mathrm{O}$ mole fractions on a cavity ring-down spectrometer (CRDS, Picarro Inc., model G2401$\mathrm{m})$. During an actual balloon flight, it usually takes $3-5 \mathrm{~h}$ from sampling until the samples are retrieved and brought back to the laboratory for analysis. Therefore, we have chosen a period of $4 \mathrm{~h}$ as the storage time to represent this time delay; i.e. the bags are stored under laboratory conditions $\left(\sim 20^{\circ} \mathrm{C}, \sim 1000 \mathrm{hPa}\right.$, ambient mole fractions of $\mathrm{CO}_{2}, \mathrm{CH}_{4}$, $\mathrm{CO}$ and $\mathrm{H}_{2} \mathrm{O}$ ) for $4 \mathrm{~h}$ before they are analysed again. The $4 \mathrm{~h}$ drift during storage is defined as the difference between the measurement after $4 \mathrm{~h}$ of storage and the initial measurement: $[X]_{4 h o u r s}-[X]_{\text {direct }}$, where $[X]$ is the measured dry mole fraction.

Previous studies show that the material of Tedlar bags is prone to water vapour diffusion (Beghi and Guillot, 2006; Cariou and Guillot, 2006), which leads to humidified air sam- 
Table 1. Components used in the LISA sampler, including manufacturer and product key. The total weight is given for amounts per part. Voltage and power are presented according to manufacturer specification. The total weight for the onboard computer and sensors is given.

\begin{tabular}{lllrrrr}
\hline Component & Company & Product key & Amount & Voltage (V) & Power (W) & Weight (g) \\
\hline Servo motor & Hitec & HS-65HB+ & 5 & $4.8-6$ & 1.32 & 91 \\
Pump & KNF & NMP 850.1.2 KNDC B & 1 & 24 & 10.8 & 403.6 \\
Bag (MLF) & Supelco & 30227-U & 4 & $(-)$ & $(-)$ & 80.4 \\
Tube Cole & Palmer & EW-95100-02 & 1 & $(-)$ & $(-)$ & 30 \\
Union tee & Swagelok & NY-400-3 & 5 & $(-)$ & $(-)$ & 39 \\
Union elbow & Swagelok & NY-400-9 & 5 & $(-)$ & $(-)$ & 33 \\
Li-battery CR123A & $(-)$ & $(-)$ & 10 & 3 & $(-)$ & 166 \\
Pressure sensor & Honeywell & HSCMAND015PASA5 & 2 & & & \\
Temperature & sensor & IST 600C (100 $\Omega)$ & 1 & $7-12$ & $(-)$ & 87.4 \\
Data logger & Arduino & Mega 2560 & 1 & & & \\
Battery casing & TruPower & BH-CR123A & 10 & $(-)$ & $(-)$ & 68.8 \\
\hline
\end{tabular}

Table 2. A total of seven sampling bags of each type (Tedlar and MLF) were prepared with the mole fractions presented below. Sampling bag nos. 6 and 7 were filled with cylinder air and were subsequently diluted using nitrogen. The results of the CRDS analysis directly after measurement are presented for those samples.

\begin{tabular}{llrrr}
\hline Sample number & $\mathrm{CO}_{2}(\mathrm{ppm})$ & $\mathrm{CH}_{4}(\mathrm{ppb})$ & $\mathrm{CO}(\mathrm{ppb})$ \\
\hline 1 & & 449.85 & 2086.2 & 260.5 \\
2 & & 398.12 & 1969.5 & 121.5 \\
3 & & 398.12 & 1969.5 & 121.5 \\
4 & & 449.85 & 2086.2 & 260.5 \\
5 & & 449.85 & 2086.2 & 260.5 \\
\hline \multirow{2}{*}{6} & MLF & 127.04 & 597.5 & 74.8 \\
& Tedlar & 110.89 & 520.4 & 62.1 \\
\hline \multirow{2}{*}{7} & MLF & 138.01 & 649.9 & 79.1 \\
& Tedlar & 125.89 & 591.1 & 71.7 \\
\hline
\end{tabular}

ples after $4 \mathrm{~h}$ of storage. $\mathrm{H}_{2} \mathrm{O}$ measurements are used to obtain dry mole fraction of $\mathrm{CO}_{2}, \mathrm{CH}_{4}$ and $\mathrm{CO}$ using the water vapour corrections described in Chen et al. (2013) and Rella et al. (2013), before assessing drift of these species.

\subsection{The storage test results}

The difference between the measured mole fractions after $4 \mathrm{~h}$ and those measured immediately after filling are shown in Fig. 2, which captures the drift over $4 \mathrm{~h}$ of storage. The drift in $\mathrm{CO}_{2}$ after $4 \mathrm{~h}$ is comparable for both types of sampling bags for sample nos. 1-5, within a range of $-0.2-0.2 \mathrm{ppm}$ (Fig. 2a). Low mole fractions of $\mathrm{CO}_{2}$, i.e. samples nos. 6 and 7 , are less stable in both types of sampling bags; however, these low mole fractions are not observed in the stratosphere, and hence the drift observed for samples nos. 1-5 is more representative than that observed for samples nos. 6 and 7 for the storage of stratospheric air samples. The $\mathrm{CH}_{4}$ mole fractions are preserved within the range of $\pm 2 \mathrm{ppb}$ for all cases for both types of sampling bags (Fig. 2b). Although the Tedlar bags perform slightly better than the MLF bags, both are satisfactory for $\mathrm{CH}_{4}$ measurements when considering its large gradient in the stratosphere $(500-2000$ ppb, e.g. Röckmann et al., 2011).

The CO mole fractions appear to be stable in the MLF bags, with no clear indication of drift, independent of the mole fractions (Fig. 2c). The variability of $\mathrm{CO}$ differences may be in large part due to the repeatability of the CRDS analyser ( $1 \sigma 7 \mathrm{ppb})$. In contrast, the $\mathrm{CO}$ mole fractions decrease in the Tedlar bags, coupled with a significant increase of water vapour mole fractions of up to $\sim 1 \%$ (Fig. $2 \mathrm{~d}$ ), which is due to the high permeability of the bag material to water vapour and has been observed in previous studies (Beghi and Guillot, 2006; Cariou and Guillot, 2006). The increase of water vapour mole fractions in the MLF bags is only up to $0.01 \%$. The observed decrease of CO mole fractions in the Tedlar bags, even when its mole fractions are lower than the ambient, cannot be explained by the permeability of the bag material, as diffusion would increase the $\mathrm{CO}$ mole fractions. Although mole fractions are corrected for water vapour to obtain dry mole fractions, we cannot exclude that there is still some remaining bias from the water vapour correction function, and this correction function was not tested before with low mole fractions. This would not affect the depicted results for the MLF bags since the water vapour content remains low. Further investigation is needed before Tedlar bags are used to collect samples for analysis of high-precision $\mathrm{CO}$ mole fractions at the ambient level.

We found out that it is necessary to precondition the MLF bags before use, because we observed a positive offset of $\sim 12$ ppm $\mathrm{CO}_{2}, \sim 8 \mathrm{ppb} \mathrm{CH}_{4}$ and $\sim 30 \mathrm{ppb} \mathrm{CO}$ between the immediately analysed results of un-preconditioned MLF bag samples after filling and the assigned cylinder values. This contamination issue could be overcome by preconditioning the bags with $\mathrm{N}_{2}$. The bags were filled with $\mathrm{N}_{2}$ from a cylinder and subsequently evacuated with a vacuum pump, prior to filling with test sample. In principle ambient air can be used to flush the bags, as long as it is dry. 
(a)

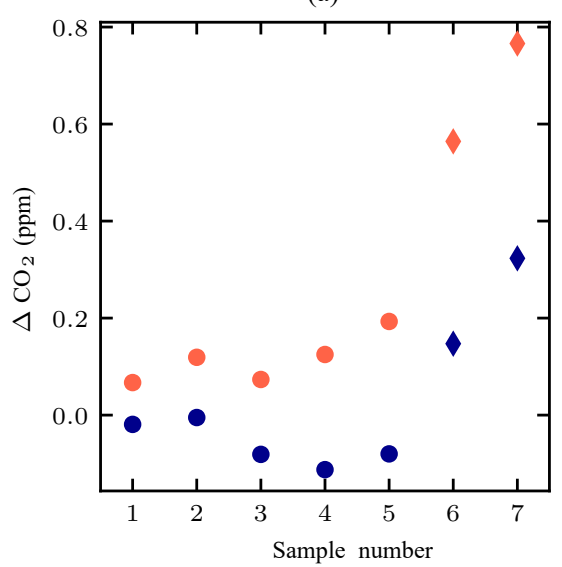

(c)

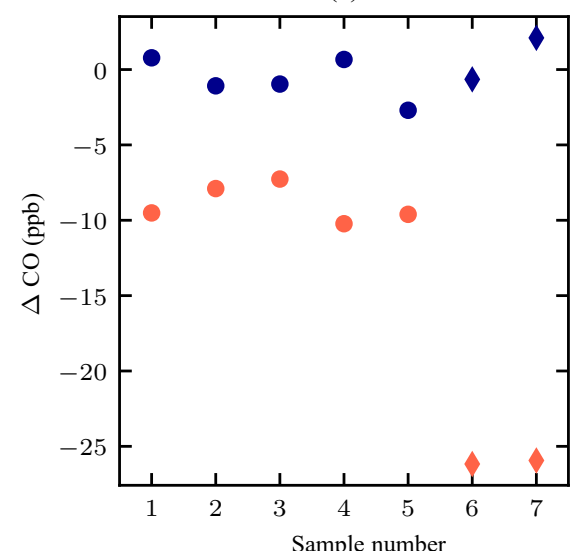

(b)

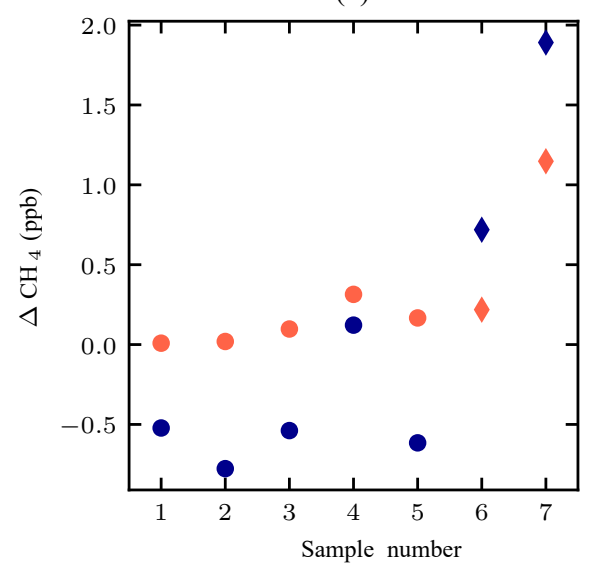

(d)

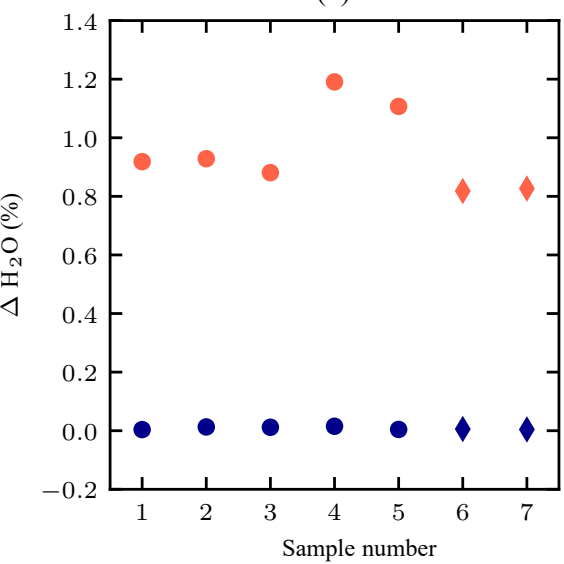

\begin{tabular}{|llll|}
\hline MLF & & MLF (low mole fraction) \\
& Tedlar & Tedlar (low mole fraction) \\
\hline
\end{tabular}

Figure 2. The observed drift of the mole fractions of $\mathrm{CO}_{2}(\mathbf{a}), \mathrm{CH}_{4}(\mathbf{b}), \mathrm{CO}(\mathbf{c})$, and $\mathrm{H}_{2} \mathrm{O}(\mathbf{d})$ in each of seven samples in both Tedlar and MLF bags. The drift is defined as the difference between the measured mole fractions after $4 \mathrm{~h}$ and those measured immediately after filling. For $\mathrm{CO}_{2}$, the mole fractions of samples nos. 1-5 are representative for stratospheric mole fractions. Samples nos. 6 and 7 contain low mole fractions and represent a typical mole fraction of stratospheric $\mathrm{CH}_{4}$.

Based on the storage test results, we choose to use the MLF bags for our sampler. The stability of the $\mathrm{CO}_{2}$ and $\mathrm{CH}_{4}$ mole fractions in both MLF and Tedlar bags is comparable; however, the observed $\mathrm{CO}$ mole fractions in Tedlar bags is less stable than those in MLF bags. In addition, the permeability of water vapour through the Tedlar bags causes a significant increase of water vapour, which may affect the isotopic composition, e.g. $\delta^{18} \mathrm{O}$ in $\mathrm{CO}_{2}$. Moreover, the aluminium layers of the MLF bag protect the air samples against radiation that could affect the stability of $\mathrm{CO}$ mole fractions. We emphasize the importance of preconditioning the MLF bags before use.

\subsection{The uncertainty of the LISA sample measurements}

We estimate the measurement uncertainty based on the laboratory storage test results and the uncertainties associated with the sample analysis. The total uncertainty of $\mathrm{CO}_{2}$, $\mathrm{CH}_{4}$ and $\mathrm{CO}$ mole fraction measurements consists of three terms: sampling error, drift due to storage and analysis uncertainty. There are two contributions to the analysis uncertainty: (1) analyser precision $\left(\sigma_{i}\right)$ and (2) calibration uncertainty $\left(\sigma_{\mathrm{c}}\right)$.

The sampling error encompasses any contamination introduced by the sampling system itself. This includes chemical production of the species of interest and residual air in any dead volumes of the manifold. The chemical production during sampling is likely to be very small for two reasons. First of all, the wetted surfaces, Kynar and EPDM diaphragm, are 
chemically inert. Secondly, the high flow rate minimizes exposure of the sample to materials used in the sampler and hence chemical interaction with the wetted surfaces is limited. In addition, the flushing procedure with high flow rates ensures multiple turnovers of the manifold, which reduces the surface effects on the sample. These effects are thus assumed to have no influence on the $\mathrm{CO}_{2}, \mathrm{CH}_{4}$ and $\mathrm{CO}$ mole fractions.

The dead volume in the tube connecting the bag to the manifold is a potential source of contamination bias. The dead volume is estimated to be $1.5 \mathrm{~mL}$ per sample and will be at local ambient pressure prior to sampling. The dead volume uncertainty, $\sigma_{\mathrm{v}}$, is estimated using a dead volume of $1.5 \mathrm{~mL}_{\text {stp }}$, which prior to sampling is assumed to be at $50 \mathrm{hPa}$ and $220 \mathrm{~K}$. This volume might remain unflushed. Hence the air is of tropospheric origin, with concentrations of $400 \mathrm{ppm}$ $\mathrm{CO}_{2}, 1800 \mathrm{ppb} \mathrm{CH} 4$ and $150 \mathrm{ppb} \mathrm{CO}$. The total sample volume is $200 \mathrm{~mL}_{\text {stp }}$ and has mole fractions of $395 \mathrm{ppm} \mathrm{CO}_{2}$, $500 \mathrm{ppb} \mathrm{CH}_{4}$ and $30 \mathrm{ppb} \mathrm{CO}$. The bias is then calculated as the resulting deviation after mixing the contamination with sample air.

The main factor likely to affect mole fraction measurements of the stratospheric air samples is the drift in the sampling bags, an effect that has been quantified in Sects. 3.1 and 3.2. In principle, one could correct for the drift as a systematic error. The drift, a consequence of diffusion through the bag's material, is governed by Fick's first and second law. A systematic correction for the drift would require the determination of the species-dependent diffusivity, which usually depends on pressure and temperature. Secondly, since diffusion depends on the concentration gradient, mole fractions of the sampler environment are needed. Hence, detailed information about storage conditions over the $3-5 \mathrm{~h}$ period between sampling and analysis is required to correct for the drift. Moreover, the information required is usually unavailable in the field. Therefore, we have not determined a correction function for the drift, but rather use the maximum observed drift as an estimate of the drift uncertainty, $\sigma_{\mathrm{d}}$. The maximum observed drift in these tests was $0.11 \mathrm{ppm}, 2 \mathrm{ppb}$ and $2.7 \mathrm{ppb}$ for $\mathrm{CO}_{2}, \mathrm{CH}_{4}$ and $\mathrm{CO}$, respectively.

Assuming Gaussian error propagation, we compute a total uncertainty on the measurements:

$\sigma_{s}=\sqrt{\sigma_{\mathrm{d}}^{2}+\sigma_{i}^{2}+\sigma_{\mathrm{c}}^{2}+\sigma_{\mathrm{v}}^{2}}$

The total uncertainty includes the analyser precision $(1 \sigma$ $0.04 \mathrm{ppm}, 0.2 \mathrm{ppb}$ and $7 \mathrm{ppb}$ for $\mathrm{CO}_{2}, \mathrm{CH}_{4}$ and $\mathrm{CO}$, respectively), the calibration uncertainty $(0.07 \mathrm{ppm}, 1 \mathrm{ppb}, 2 \mathrm{ppb}$ for $\mathrm{CO}_{2}, \mathrm{CH}_{4}$ and $\mathrm{CO}$, respectively), and the aforementioned drift. The different uncertainties are summarized in Table 3. We compute the total uncertainty of the LISA sample measurements to be $0.14 \mathrm{ppm}, 2.3 \mathrm{ppb}$ and $7.8 \mathrm{ppb}$ for $\mathrm{CO}_{2}, \mathrm{CH}_{4}$ and $\mathrm{CO}$, respectively.
Table 3. Uncertainty based on the different error sources for $\mathrm{CO}_{2}$, $\mathrm{CH}_{4}$ and $\mathrm{CO}$. The total uncertainty is calculated using Gaussian error propagation.

\begin{tabular}{lrrr}
\hline Source & $\mathrm{CO}_{2}(\mathrm{ppm})$ & $\mathrm{CH}_{4}(\mathrm{ppb})$ & $\mathrm{CO}(\mathrm{ppb})$ \\
\hline Analyser & 0.04 & 0.2 & 7 \\
Calibration transfer & 0.07 & 1 & 2 \\
Dead volume* & 0.002 & 0.605 & 0.056 \\
Storage drift & 0.11 & 2.0 & 2.7 \\
Total & 0.14 & 2.3 & 7.8 \\
\hline
\end{tabular}

* The dead volume bias is estimated using a dead volume of $1.5 \mathrm{~mL}$ stp, which prior to sampling is assumed to be at $50 \mathrm{hPa}$ and $220 \mathrm{~K}$. This volume might remain unflushed. Hence the air is of tropospheric origin, with concentrations of $400 \mathrm{ppm}$ $\mathrm{CO}_{2}, 1800 \mathrm{ppb} \mathrm{CH}_{4}$ and $150 \mathrm{ppb} \mathrm{CO}$. The total sample volume is $200 \mathrm{~mL}_{\text {stp }}$ and has mole fractions of $395 \mathrm{ppm} \mathrm{CO}_{2}, 500 \mathrm{ppb} \mathrm{CH}_{4}$ and $30 \mathrm{ppb} \mathrm{CO}$. The bias is then calculated as the resulting deviation after mixing.

\section{The vertical resolution and the pump performance}

The vertical resolution of each individual air sample depends on the vertical speed of the sampler during flight, and the effective sampling time, i.e. when the flow rate into the sampling bag is positive. On the other hand, the amount of air sample collected into each sampling bag is determined by the sampling time and the sampling flow rate. Due to the tradeoff between the vertical resolution and the sample size, we evaluate the pump performance to assist the choice of the sampling time.

Under laboratory conditions the KNF pump can maintain a flow rate of up to $8 \mathrm{~L}_{\mathrm{stp}} \mathrm{min}^{-1}$. The performance of the small diaphragm pump is, to our knowledge, not previously investigated under the atmospheric conditions in the stratosphere, e.g. in low temperature and low pressure conditions.

We evaluated the sampling performance using a simplified version of the sampler under simulated conditions in the laboratory. The test version of the sampler consisted of the KNF pump, the outlet valve and one sampling bag, supported by the required electronics (pressure and temperature sensors, a data logger and batteries). The test version was placed in a $50 \mathrm{~L}$ vessel for testing. The pressure inside the vessel was regulated by a vacuum pump, mimicking the atmospheric pressure levels in the stratosphere. After a desired pressure level was reached, the vacuum pump was switched off, and the sampler sampled air for $153 \mathrm{~s}$. The experiment was repeated at three different pressure levels. Using the manifold pressure and temperature data within the vessel, logged at $3 \mathrm{~Hz}$, we calculate the sampled air volume at STP using the ideal gas law as a function of sampling time. The experiments were performed at room temperature.

The pressure readings are initially constant, while the bag is expanding to its full size of $2.58 \mathrm{~L}$. Afterwards, the pressure starts to increase when air is compressed. We assume that the bag has expanded to its full size when the pressure starts to increase. Furthermore, the results allowed us to create a simple empirical model to calculate the sampled air vol- 
ume as a function of sampling time at all pressure levels. It provides a useful tool to quickly estimate the expected sample size and vertical resolution during field campaigns.

Figure 3a shows the sampled air volume at STP as a function of the sampling time in seconds, for three different pressure levels $(31.5,60.8$ and $117.7 \mathrm{hPa})$ in the vessel. The volume is calculated with the ideal gas law, using the logged manifold pressure and temperature. The volume of the bag is estimated to be $2.58 \mathrm{~L}$. The $3 \mathrm{~Hz}$ pressure data were averaged into $5 \mathrm{~s}$ bins, to reduce the random noise of the pressure measurements and to smooth the pressure wave induced by the stroke of the pump. The sampled air volume increases linearly with the sampling time when the bag expands to its full size during the first $20 \pm 1 \mathrm{~s}$. The moment compression is required, pressure starts increasing rapidly, and this moment was found to be $20 \mathrm{~s}$ after filling initiated. Afterwards, the increase rate slows down due to reduced flow rates that result from the increasing pressure difference across the pump. The gain in sampled air volume within equal sampling time thus becomes less at longer sampling time.

Furthermore, we show the sampled air volume as a function of the vessel pressure in Fig. 3b. Here the sampling times of 50, 100 and $150 \mathrm{~s}$ are arbitrarily chosen. For each sampling time, the sampled air volume is interpolated from the data shown in Fig. 3a and appears to be linear with the vessel pressure. Hence, we fit the following linear equation to the derived data in Fig. 3b,

$V_{\text {stp }}=a(t) p_{\mathrm{a}}$,

where $p_{\mathrm{a}}\left(\mathrm{in} \mathrm{hPa}\right.$ ) is the ambient pressure in the vessel, $V_{\text {stp }}$ is the sample amount in litre at STP and a is a function of the sampling time $\left(\mathrm{L}_{\mathrm{stp}} \mathrm{hPa}^{-1}\right)$. We performed a series of linear fits for the sampling time ranging from 0 to $150 \mathrm{~s}$ at an interval of $10 \mathrm{~s}$, and derived corresponding linear coefficients $a(t)$ as a function of sampling time (see Fig. 3c). To model $V_{\text {stp }}$ as a function of pressure $p_{\mathrm{a}}$ and sampling time $t$, the linear coefficient $a(t)$ in Eq. (2) is empirically modelled using the following function:

$a(t)=x-b e^{\frac{-\left(t-t_{0}\right)}{\tau}}$,

where $t$ is sampling time and $x, b$ and $\tau$ are constant parameters used for the fit. $t_{0}=19.7 \mathrm{~s}$ is the time required to fill the bag up to chamber pressure, and the model is only valid for $t>19.7 \mathrm{~s}$. Equation (3) is fitted using the non-linear least squares method to obtain an empirical model for the slope $a(t)$ in Eq. (2).

Combining Eqs. (2) and (3), the sampled volume at STP can be approximated for all pressure levels ranging from 200 to $0 \mathrm{hPa}$ for any chosen sampling time. The derived sample volume is shown as a function of ambient pressure or altitude in Fig. 3d for the sampling time of 50, 100, 200 and 1000 s, respectively. The International Standard Atmosphere is used to link ambient pressure and altitude. The gain in the sample size from 200 to $1000 \mathrm{~s}$ of sampling is very small due to the saturation of the pumping capacity; however, the vertical resolution would on the other hand be compromised severely. Assuming an ascent speed of the balloon of $5 \mathrm{~m} \mathrm{~s}^{-1}$, the corresponding vertical resolutions would be 1 and $5 \mathrm{~km}$ for the sampling time of 200 and $1000 \mathrm{~s}$, respectively.

An upper limit to the amount of air samples in the MLF bag was found due to its sealing capacity. The bag's seal was observed to break when a differential pressure of $\sim 300 \mathrm{hPa}$ between the inside and the outside of the bag is reached. The maximum allowed pressure serves as a practical limit to the sample size that can be achieved, which is presented in Fig. 3b with a horizontal line, and in Fig. 3d with a vertical line. During flight, the payload is usually lifted up to $\sim 30 \mathrm{~km}$ $(\sim 10 \mathrm{hPa})$, which means the pressure inside the MLF bag can be at maximum $\sim 310 \mathrm{hPa}$. Conservatively, we set the maximum absolute pressure in the MLF bag during flight no higher than $280 \mathrm{hPa}$ to avoid any potential loss of sample due to the burst of the bag.

The model provides a good tool to design the sampling strategy in the field. It should be noted that the simplification of the model causes uncertainties in the estimated sample size. On the one hand, this model does not take the temperature in the real conditions into account. Since air in the stratosphere is usually cold, e.g. $220 \mathrm{~K}$, the total sampled volume at STP would be larger than the modelled, due to thermal expansion. On the other hand, the model assumes a constant upstream pressure, whereas the upstream pressure decreases during flight, and hence the total sampled volume at STP would then be smaller than the modelled.

\section{Flights and validation}

Following the laboratory experiments described above, we deployed the sampler in the field. A total of four flights were performed in Sodankylä, Finland $\left(67.368^{\circ} \mathrm{N}, 26.633^{\circ} \mathrm{E}\right.$; 179 ma.s.l.), at the Finnish Meteorological Institute's Total Carbon Column Observing Network (TCCON) facility (Kivi and Heikkinen, 2016). The facility includes a highresolution Fourier transform spectrometer installation to retrieve column-averaged abundances of atmospheric constituents, gas analysers for in situ measurements and both manual and automatic radiosonde systems. The flights were performed on four different days, on 26 April and 46 September 2017, respectively. We aimed to collect four air samples during each flight at four preset pressure altitudes. The settings of the sampling parameters are summarized in Table 4 . The sampling parameters varied from flight to flight, to test the capabilities of the sampler.

The payload consisted of an AirCore, LISA Sampler, a payload positioning system that uses both Iridium and GPS/GSM positioning, a lightweight transponder and a Vaisala RS92-SGP radiosonde (Dirksen et al., 2014). This configuration allowed for a direct comparison between AirCore and sampler measurements. The AirCore used during 
(a)

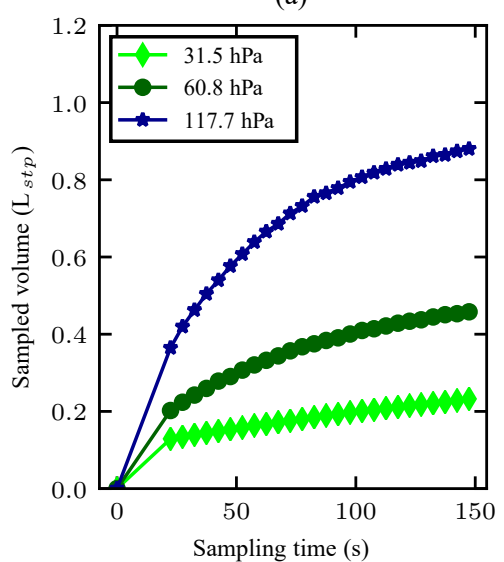

(c)

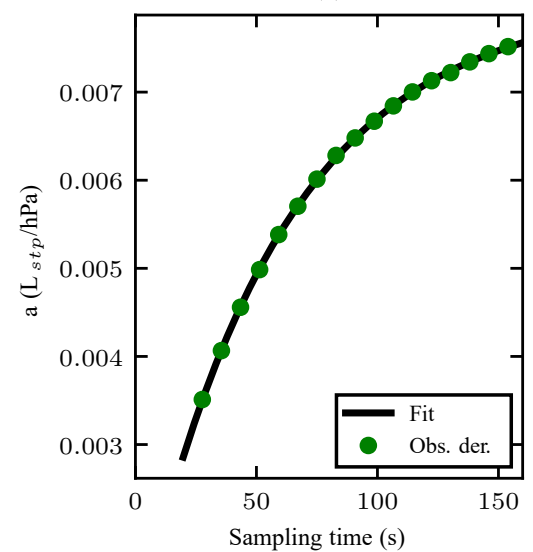

(b)

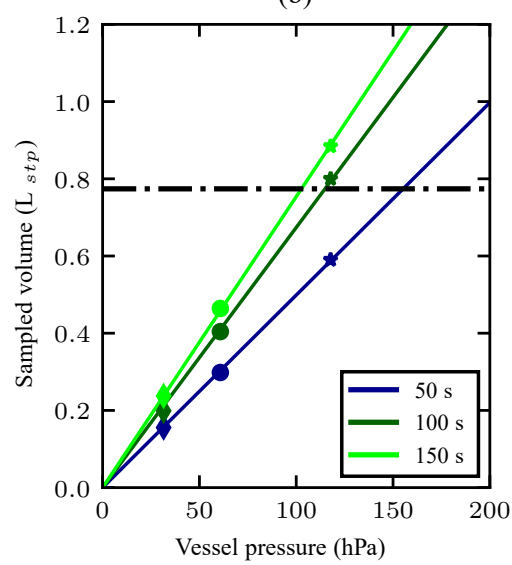

(d)

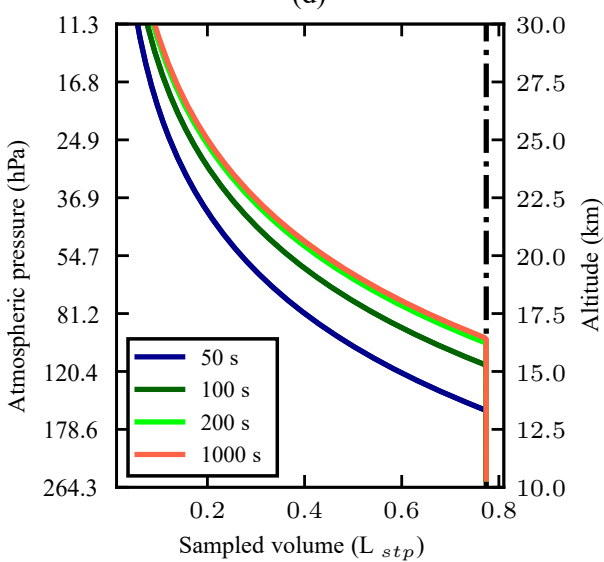

Figure 3. (a) Sample volume as a function of the sampling time in seconds. The first $19.7 \mathrm{~s}$ fill the bag up to the pressure in the vessel. The sampled volume in the first $19.7 \mathrm{~s}$ linearly interpolated starting at zero, e.g. assuming that sampled volume increases linearly with time. After the first $19.7 \mathrm{~s}$, the bag is no longer expanding and air needs to be compressed and the flow rate drops. (b) Sampled volume in litres at STP as a function of vessel pressure (markers correspond to those presented in 3a). The sampling times of 50, 100 and $150 \mathrm{~s}$ are arbitrarily chosen. The lines are a linear fit to the data as in Eq. (2). For a given sampling time, the sampled amount at STP decreases linearly with vessel pressure. The bags cannot withstand a pressure difference larger than $300 \mathrm{hPa}$. The practical limit is presented with a black dashed line. (c) The slope $a(t)$ (Eq. 2) as a function of sampling time. The data points are derived values of $(t)$ from the pressure data (Obs. der. is observations-derived), and the black line is the applied fit to the data, according to Eq. (3), with $t_{0}=19.7 \mathrm{~s}$. (d) Atmospheric pressure on the left and corresponding altitude on the right, as a function of modelled sampled volume. Note that for atmospheric pressure $>120$ and $<30 \mathrm{hPa}$, as well as for sampling time $>150$ the depicted model relies on extrapolation of the observations. The International Standard Atmosphere is used to link pressure and altitude. The cut-off at the sample size of $0.77 \mathrm{~L}_{\text {stp }}$ is due to the practical fill limit of $300 \mathrm{hPa}$ which consequently means that the sampling time is less. The uncertainty in volume presented in panels $(\mathbf{a}, \mathbf{b})$ is $7.6 \mathrm{~mL}$ stp.

Table 4. Preset sampling parameters. Sampling is completed after either the maximum pressure in the manifold or the maximum sampling time is reached. P1-P4 are the preset targeted pressure altitudes.

\begin{tabular}{lrrrrrr}
\hline Date & $\begin{array}{r}\text { Maximum } \\
\text { sampling time (s) }\end{array}$ & $\begin{array}{r}\text { Maximum } \\
\text { pressure }(\mathrm{hPa})\end{array}$ & $\begin{array}{r}\mathrm{P} 1 \\
(\mathrm{hPa})\end{array}$ & $\begin{array}{r}\mathrm{P} 2 \\
(\mathrm{hPa})\end{array}$ & $\begin{array}{r}\mathrm{P} 3 \\
(\mathrm{hPa})\end{array}$ & $\begin{array}{r}\mathrm{P} 4 \\
(\mathrm{hPa})\end{array}$ \\
\hline 26 April 2017 & 250 & 250 & 200 & 150 & 100 & 50 \\
4 September 2017 & 180 & 275 & 200 & 150 & 100 & 50 \\
5 September 2017 & 220 & 280 & 170 & 120 & 80 & 30 \\
6 September 2017 & 250 & 280 & 170 & 120 & 80 & 50 \\
\hline
\end{tabular}


the campaign consists of two pieces of stainless steel tubing (40 $\mathrm{m}$ long $1 / 4 \mathrm{in.} \mathrm{OD} \mathrm{and} 60 \mathrm{~m}$ long $1 / 8 \mathrm{in}$. OD, wall thickness $0.01 \mathrm{in}$.), with a total weight of $\sim 3.6 \mathrm{~kg}$. The LISA sampler package weighed $2.8 \mathrm{~kg}$. After retrieval of the payload, the samples were analysed in the TCCON laboratory for $\mathrm{CO}_{2}, \mathrm{CH}_{4}$ and $\mathrm{CO}$ mole fractions using the same CRDS analyser as used in our laboratory, whereas the AirCore sample analysis was done on a second CRDS analyser for $\mathrm{CO}_{2}$, $\mathrm{CH}_{4}$ and $\mathrm{CO}$ mole fractions. Two different sets of calibration gases were used for the AirCore and the sampler sample analysis. Although both sets of calibration gases are ultimately on the same scales $\left(\mathrm{CO}_{2}\right.$ : X2007, $\mathrm{CH}_{4}$ : X2004A and CO: X2014A), we cross-checked the calibration gases on one CRDS analyser to eliminate any difference that may exist between the two sets of calibration gases.

During the flights, temperature, air pressure and pressure in the manifold were logged with a frequency of $0.8 \mathrm{~Hz}$. The temperature was measured near the batteries and pump, for diagnostic purposes. Ambient atmospheric temperature was measured with the radiosonde. The logged pressure and radiosonde temperature data allowed us to quantify the sample size (Sect. 5.2) and to calculate the pressure-weighted mean altitude of the samples (Sect. 5.1). The altitude provided by the radiosonde is used for calculation of the vertical resolution of the samples (Sect. 5.2).

The 15 samples were successfully obtained from four flights. During the first flight on 26 April 2017, only time and the start and end time of sampling were logged due to a malfunction in the data logger. As the time stamp of the data logger is reported in UTC, we are able to sync the sampling information from the data logger with atmospheric measurements of temperature, pressure and altitude from the radiosonde on the same payload. This is subsequently used to estimate the vertical resolution and the sample size using the empirical derived function in Sect. 4. During the same flight, the AirCore data logger failed to record any data (e.g. coil temperature, valve closing time), and the temperature data from a flight performed 2 days earlier, on 24 April 2017, have been used to retrieve the AirCore profiles. During the flight on 4 September 2017, the sampler was unsuccessful to take a sample at the $200 \mathrm{hPa}$ pressure level, because the maximum allowed pressure in the manifold was reached during the short time between the closure of the outlet valve and opening of the sampling bag. Reversing the order of closure of the outlet valve and opening of the sampling bag fixes this problem.

\subsection{The weighted mean sampling pressure of the samples}

During sampling of each bag, the atmospheric pressure decreases as the payload ascends, and the volume flow rate drops due to a nonlinear increase of pressure in the bag. Therefore, not all atmospheric pressure levels contribute equally to the collected sample in size or mole fractions of trace gases. The integrated sample thus has an associated pressure-weighted mean altitude. The contribution of each pressure level to one sample is proportional to the number of moles of air sampled at that pressure level. In general, the first $19.7 \mathrm{~s}$ of sampling contributes the most and the end of sampling contributes the least to the collected sample. When pressure and temperature within the manifold are measured, the number of moles of air at each pressure level can be computed directly, and the weight of that pressure level will be

$w_{i}=\frac{\mathrm{d} n_{i}}{n}$,

where $\mathrm{d} n_{i}$ is the number of moles of air sampled at the pressure level $p_{i}, n$ is the total number of moles of collected air samples. $w_{i}$ is then the weight of the air samples collected at the pressure level $p_{i}$. The pressure-weighted mean pressure altitude $\bar{p}$ can be calculated as follows:

$\bar{p}=\Sigma w_{i} p_{i}$

The first $19.7 \mathrm{~s}$ of sampling cannot be calculated directly, since $\mathrm{d} p_{i}=0$; i.e. no compression and the pressure inside the bag is the same as outside. We assign the first weight that can be calculated to the first $19.7 \mathrm{~s}$ of sampling.

The temperature of the air samples in the bag was not directly measured. For the calculation of the pressure-weighted mean sampling pressure of the samples, we assume constant temperature of the sampled air while sampling. In reality, the temperature of the air samples in the bag would be close to the ambient temperature as the bag is directly exposed to the ambient air. Since the observed variability of the ambient temperature during sampling is usually less than $1 \mathrm{~K}$ $(1 \sigma)$, the assumption of constant temperature during sampling causes insignificant uncertainty on the weighted mean sampling pressure.

\subsection{Vertical resolution and sample size}

Both the volume of the collected air samples (Fig. 4a) and vertical resolution decreases (Fig. 4b) with increasing altitude. The sample size achieved by the sampler is close to that estimated based on the empirical model shown in Sect. 4. The variability of the collected sample size can be mostly explained by the different settings for the sampling time and the maximum allowed pressure during different flights (see Table 4). Furthermore, the cold temperatures in the stratosphere result in denser air, so the observed sample sizes are slightly higher, especially in the lower stratosphere.

The variability in the vertical resolution is the result of three factors: (1) varying sampling time; (2) varying ascending speed; (3) varying maximum allowed pressure. The ascending speed was typically around $7-9 \mathrm{~m} \mathrm{~s}^{-1}$ in the lower stratosphere and decreased to $4-5 \mathrm{~m} \mathrm{~s}^{-1}$ in the middle stratosphere. The varying ascending speed accounts for the observed deviations from the otherwise linear trend in Fig. 4b. In the lower stratosphere 10 to $15 \mathrm{~km}$ the maximum allowed 
(a)

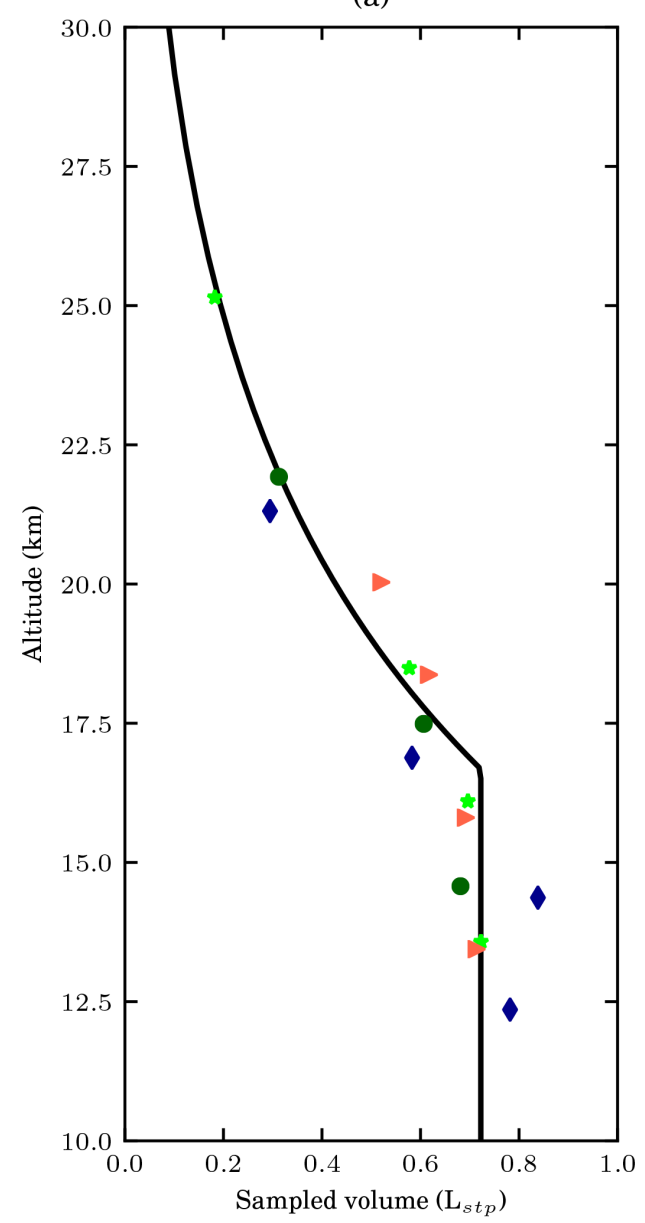

(b)

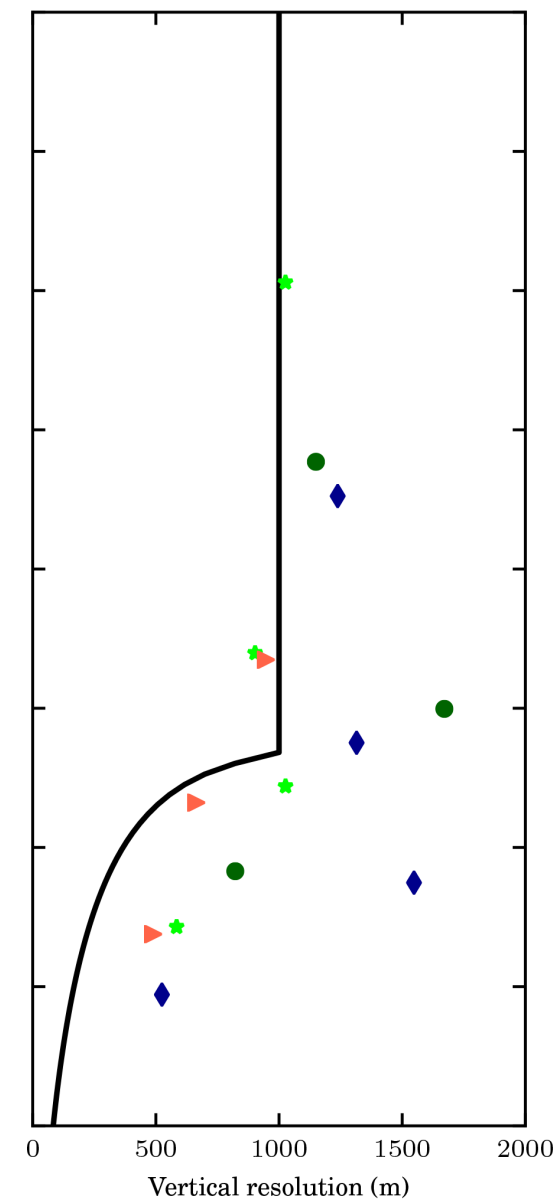

\begin{tabular}{|llllll|}
\hline & Sampler 26-04 & Sampler 04-09 $\quad$ Sampler 05-09 & Sampler 06-09 \\
\hline
\end{tabular}

Figure 4. (a) The altitude profile of the sample size of the collected 15 air samples. The estimated sample size with the sampling time of $200 \mathrm{~s}$, and a maximum allowed bag pressure of $280 \mathrm{hPa}$, using the empirical relations used in Sect. 4 is shown plotted in black, similar to in Fig. 3d. The uncertainty in volume presented is $7.6 \mathrm{~mL}$. (b) The altitude profile of the vertical resolution of the collected samples. Different colours and symbols are used to label the samples from different flights. The vertical resolution of the highest sample from the flight on 6 September 2017 is not shown as the number is abnormally large caused by fast descending speed after the burst of the balloon. The black solid line sows the expected vertical resolution, assuming an ascent speed of $5 \mathrm{~m} \mathrm{~s}^{-1}$. Sampling time is calculated using the empirical relations discussed in Sect. 4, with a maximum allowed pressure of $280 \mathrm{hPa}$. If this is not reached we have used the maximum sampling time of $200 \mathrm{~s}$, which corresponds to a vertical resolution of $1 \mathrm{~km}$.

pressure inside the bags was usually reached in a period shorter than the preset sampling time, leading to relatively high vertical resolution. In the region 10 to $15 \mathrm{~km}$ two samples deviate (4 September, $17 \mathrm{~km}$ and 26 April, $14 \mathrm{~km}$ ), with lower resolution, which is due to a higher ascending speed. In the middle stratosphere, the sampling time was usually the limiting factor to vertical resolution. One sample in the middle stratosphere has a relatively good vertical resolution (5 September, $25 \mathrm{~km}$ ), which is due to the relatively slow ascent speed.

While the sampler was still collecting the last sample during the flight on 6 September 2017, the balloon burst at a lower altitude $(21.4 \mathrm{~km})$ than previous flights. The verti- cal resolution of that particular sample was estimated to be $3.1 \mathrm{~km}$ (not shown), a number much larger than that of other samples due to the fast descending speed of $16.8 \mathrm{~m} \mathrm{~s}^{-1}$ after burst.

\subsection{Comparison with AirCore measurements}

The vertical profiles of $\mathrm{CO}_{2}, \mathrm{CH}_{4}$ and $\mathrm{CO}$ mole fractions from both AirCore and LISA measurements are presented in Fig. 5. For the retrieval of the AirCore profiles we refer to Chen et al. (2018). AirCore and LISA measurements are compared based on the same pressure level. For a fair comparison, we averaged the AirCore profiles with the same 
Table 5. Comparison of $\mathrm{CO}_{2}, \mathrm{CH}_{4}$ and $\mathrm{CO}$ mole fractions between AirCore and LISA measurements. The difference is calculated as LISA minus AirCore. The correlation coefficient between LISA and averaged AirCore is also presented.

\begin{tabular}{lrcrc}
\hline Species & Mean $\pm \sigma$ & $\mathrm{R}^{2}$ & Mean $\pm \sigma^{*}$ & $\mathrm{R}^{2 *}$ \\
\hline $\mathrm{CO}_{2}(\mathrm{ppm})$ & $0.84 \pm 0.47$ & 0.93 & $0.55 \pm 0.13$ & 0.97 \\
$\mathrm{CH}_{4}(\mathrm{ppb})$ & $1.8 \pm 16.2$ & 0.99 & $-5.1 \pm 13.1$ & 0.99 \\
$\mathrm{CO}(\mathrm{ppb})$ & $6.3 \pm 6.6$ & 0.58 & $-9.2 \pm 5.2$ & 0.59 \\
\hline
\end{tabular}

* Excluding the April 26 flight.

weights that are used to calculate the weighted mean sampling pressure of the samples. The mean differences between LISA and AirCore measurements of $\mathrm{CO}_{2}, \mathrm{CH}_{4}$ and $\mathrm{CO}$ mole fractions are summarized in Table 5.

A relatively large difference in the $\mathrm{CO}_{2}$ mole fractions ( $>1 \mathrm{ppm}$ ) between LISA and AirCore is clearly visible for the flight on 26 April 2017. The observed difference is much larger than the uncertainty caused by the drift of $\mathrm{CO}_{2}$ mole fractions due to storage in the MLF bag (shown in Fig. 2a) and cannot be explained by any known reasons. The differences of the $\mathrm{CO}_{2}$ mole fractions for other flights are significantly smaller. The summertime stratosphere is only affected by weak diabatic stirring (Holton et al., 1995; Plumb, 2002, 2007), and can be considered relatively stable. Therefore, the flights on 4-6 September 2017 can be, to a large extent, considered duplicate measurements. This is supported by the excellent agreement between the AirCore profiles of $\mathrm{CO}_{2}$ and $\mathrm{CH}_{4}$ mole fractions measured on those dates. The AirCore data logger failure on 26 April 2017 may cause increased uncertainty in the altitude registration of the AirCore measurements, whereas the malfunction of the LISA data logger during the same flight may cause increased uncertainty in the weighted mean sampling pressure of the samples. Therefore, we also calculated the mean differences excluding the flight on 26 April 2017, which decreases the mean difference in $\mathrm{CO}_{2}$, but slightly increases the difference in $\mathrm{CO}$.

$\mathrm{CO}$ mole fractions agree well during all flights, except that a small decrease with altitude was observed by LISA measurements in September 2017, but not captured by AirCore measurements. A good agreement between AirCore and LISA CO measurements is found for the flight on 26 April 2017. Besides this, an interesting CO plume at $13.5 \mathrm{~km}$ is observed by both AirCore and LISA during the flight on 5 September 2017.

\section{Discussion}

\subsection{LISA sampler comparison with AirCore measurements}

The deviation between AirCore and sampler results is on average $0.84 \mathrm{ppm}$ for $\mathrm{CO}_{2}$, a result that is comparable in mag- nitude to AirCore inter-comparisons (e.g. Engel et al., 2017; Membrive et al., 2017). For methane, we find a mean deviation of $1.8 \mathrm{ppb}$, within the uncertainties of both AirCore and LISA (see Sect. 3.3). CO also shows a good agreement within the measurement uncertainty of CO by the CRDS analyser. Several aspects are considered that could explain the observed differences. First of all, the altitude registration of AirCore measurements is associated with uncertainties, as outlined by Membrive et al. (2017), especially due to the manual selection of the start and the end of AirCore sample analysis or any potential loss of air samples in case of valve malfunction, which complicates the comparison between AirCore and the sampler. Secondly, there are uncertainties associated with the calculation of AirCore pressure-weighted mean and mole fractions. The AirCore profile needs to be weighted for a fair comparison, since air samples at different altitudes (or pressure levels) do not contribute equally to the sampler samples. The uncertainty in altitude of the AirCore profile adds a level of uncertainty to the AirCore pressure-weighted mean. Finally, the retrieved AirCore profiles are already smoothed due to molecular diffusion and Taylor dispersion, and smearing effects in sample renewal of the cavity of the CRDS. For more information on the uncertainties associated with AirCore profiles we refer to Engel et al. (2017), Karion et al. (2010), and Membrive et al. (2017).

In the first flight on 26 April, an averaged difference of $\sim 1 \mathrm{ppm}$ in $\mathrm{CO}_{2}$ is observed, which cannot be explained by the associated uncertainties or by smoothing of the AirCore profile due to diffusion. The samples were taken at a distance no more than $1.5 \mathrm{~km}$ apart (determined from Vaisala GPS-data) in the stratosphere, with less than $1.5 \mathrm{~h}$ in between LISA and AirCore sampling. Such large horizontal mole fraction gradients are not expected in the stratosphere, although stratospheric dynamics in winter show a higher degree of variability in measured trace gases. The AirCore valve did not close during the 26 April 2017 flight. This complicates the altitude registration of the AirCore, especially on the lowest part of the profile. The influence on the stratospheric part of the profile is limited, which can be seen from the large degree of agreement in $\mathrm{CH}_{4}$ profiles between AirCore and LISA.

Another potential source for the bias is out-gassing from the packaging material and the balloon. As the ambient pressure decreases during ascent of the balloon flight, the desorption of trace gases from the surface of the packaging material and the balloon occurs, which potentially influences the mole fractions of the air samples. This would, however, not explain the good agreement during the September flights. Furthermore, the inlet is located at the top of the payload and any out-gassing from the packaging material would be flushed away from the inlet during ascent.

The seasonality in tropospheric $\mathrm{CO}_{2}$ that causes the difference between sampled air and its storage environment could contribute to the observed difference. The Northern Hemisphere winter $\mathrm{CO}_{2}$ mole fractions are typically $10 \mathrm{ppm}$ 
(a)

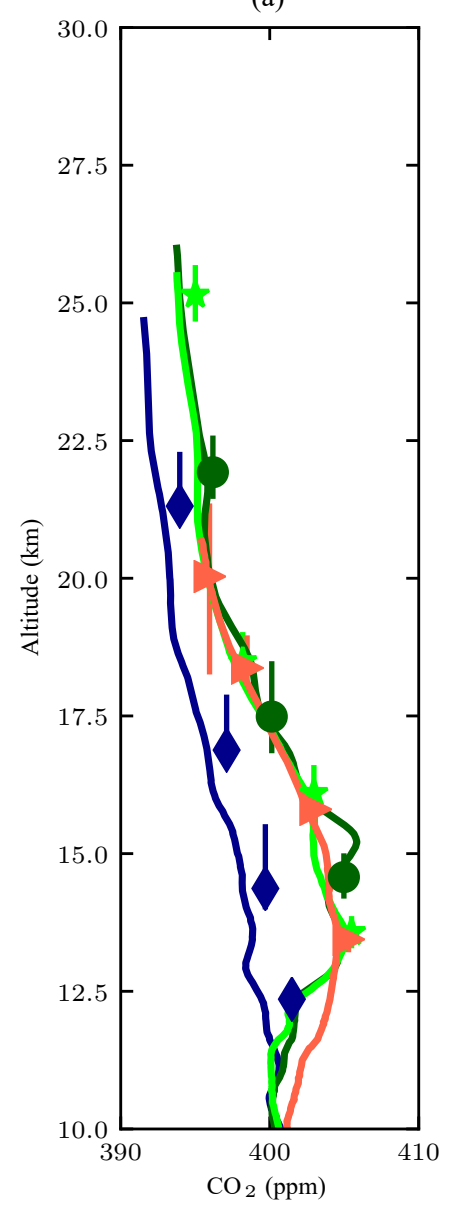

(b)

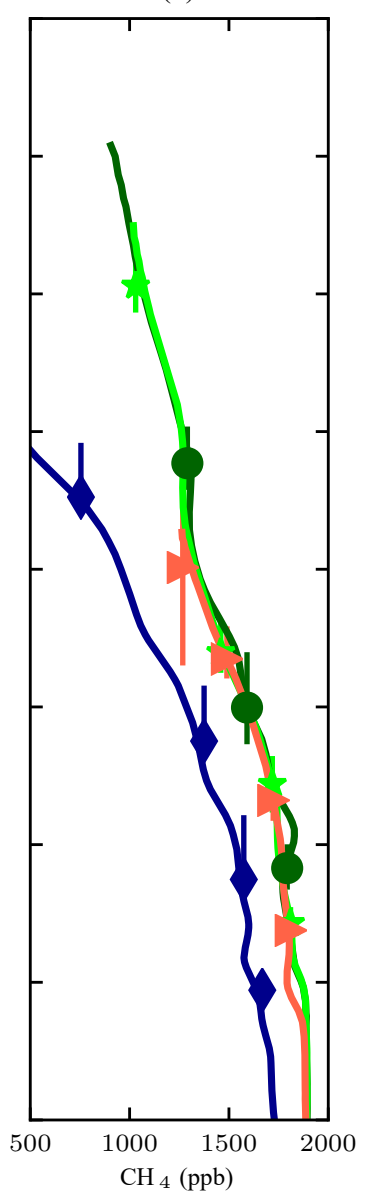

(c)

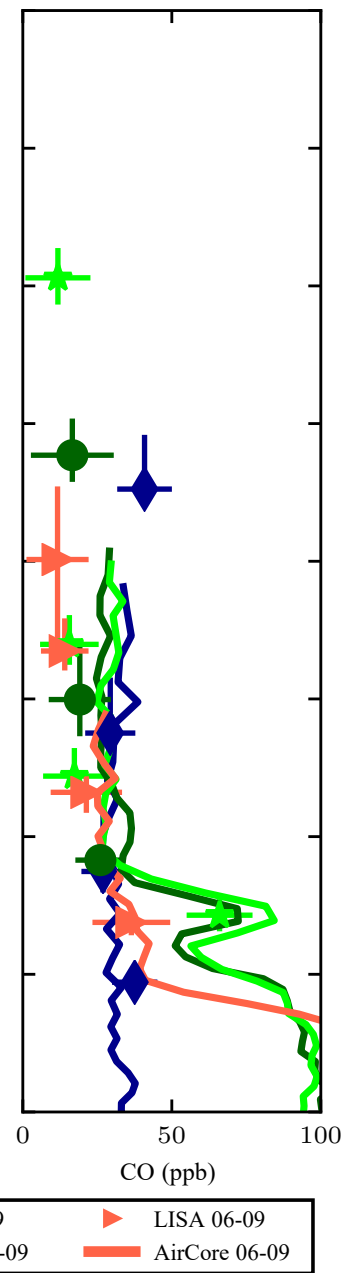

Figure 5. Comparison of AirCore and LISA measurements of (a) $\mathrm{CO}_{2}$, (b) $\mathrm{CH}_{4}$ and (c) $\mathrm{CO}$ mole fractions. The AirCore $\mathrm{CO}$ profiles are averaged in $100 \mathrm{~m}$ bins to smooth the relatively large noise of the measurements due to the analytical precision of $7 \mathrm{ppb}(1 \sigma)$ of the CRDS analyser. Different colours and symbols are used to label the samples from different flights shown in the legend. All flights were performed in 2017 .

higher those in summer. During the storage test with low mole fractions, e.g. sample nos. 6 and 7 in Fig. 2, a drift of up to $0.8 \mathrm{ppm}$ was observed. Therefore, a typical seasonal difference of $10 \mathrm{ppm}$ could only explain a difference of $0.03 \mathrm{ppm}$ in the observed $\mathrm{CO}_{2}$ bias.

As seen from Table 5, the mean deviation for $\mathrm{CO}_{2}$ reduces from 0.84 to $0.55 \mathrm{ppm}$, when the 26 April 2017 flight is excluded. Still, the sampler shows consistently higher $\mathrm{CO}_{2}$ mole fractions than AirCore, which suggests that a small unexplained bias might exist in the LISA $\mathrm{CO}_{2}$ mole fraction measurements compared to AirCore. $\mathrm{CH}_{4}$ and $\mathrm{CO}$ on the other hand show an excellent agreement within measurement uncertainties, which suggests that no significant bias exists within the measurement uncertainties for $\mathrm{CH}_{4}$ and $\mathrm{CO}$.

\subsection{Vertical resolution and sample size}

The vertical resolution of the collected stratospheric air samples ranges from 500 to $1500 \mathrm{~m}$, and the sample size ranges

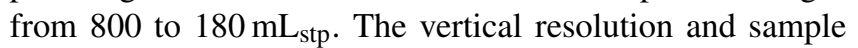
size thus outperform the AirCore. The vertical resolution and sample size of the LISA sampler is compared to the performance of AirCore sub-sampled air in Table 6. Its shows that sampler outperforms the sub-sample method described in Paul et al. (2016) and Mrozek et al. (2016).

As mentioned previously, the vertical resolution depends on the ascending speed and the effective sampling time, and the sample size also depends on the effective sampling time. To this end, the effort in collecting more air samples by increasing the effective sampling time will compromise the vertical resolution. The vertical resolution can be improved 
Table 6. Comparison of the vertical resolution and sample size between the LISA sampler and samples sampled from AirCore. Reference samples used in this table are as follows: (A) Mrozek et al. (2016); (B) Paul et al. (2016); (C) this study.

\begin{tabular}{llrrl}
\hline Altitude $(\mathrm{km})$ & Method & Resolution $(\mathrm{m})$ & Sample size $(\mathrm{mL})$ & Reference \\
\hline \multirow{3}{*}{12} & AirCore & 800 & 25 & A \\
& AirCore & 1000 & 50 & $\mathrm{~B}$ \\
& LISA & 580 & 720 & $\mathrm{C}$ \\
\hline \multirow{3}{*}{15} & AirCore & 1500 & 25 & $\mathrm{~A}$ \\
& AirCore & 2000 & 50 & $\mathrm{~B}$ \\
& LISA & 820 & 680 & $\mathrm{C}$ \\
\hline \multirow{3}{*}{20} & AirCore & 2000 & 25 & $\mathrm{~A}$ \\
& AirCore & 3000 & 50 & $\mathrm{~B}$ \\
& LISA & 1100 & 312 & $\mathrm{C}$ \\
\hline \multirow{2}{*}{25} & AirCore & 3000 & 25 & A \\
& AirCore & 5000 & 50 & $\mathrm{~B}$ \\
& LISA & 1000 & 182 & $\mathrm{C}$ \\
\hline
\end{tabular}

by lowering the ascending speed and decreasing the sampling time. The pump works most effectively when the pressure difference across it is minimal. From the results shown in Fig. 3d, we see that after $200 \mathrm{~s}$ of sampling, the gain in sample amount decreases quickly. Therefore, the gain in sample amount, for example adding 10 extra seconds of sampling time, is small; however, the decrease in vertical resolution is significant.

During the experiments described in Sect. 4, the pump was at room temperature. The pump performance could be affected by the cold environment. First, the batteries could lose capacity and cause the power supplied to the pump to decrease. The temperature inside the thermally insulated package, where the pump is located, during flight ranged between 30 and $-15^{\circ} \mathrm{C}$. Secondly, the diaphragm is exposed to the cold air passing through the pump. The elasticity of a rubber is temperature dependent, which could reduce the performance of the pump. On the other hand, heat is released during operation of the pump, which increases the temperature. Finally, the effect of air temperature on sample size follows the ideal gas law, and the sample size increases at low temperatures. As no experimental data are available to determine the performance of the pump at stratospheric temperature, we assume that the pump performs the same during flight as at room temperature for the calculation of the sample size.

The sample size can be increased by using an alternative pump that can deliver a higher flow rate than the current $8 \mathrm{~L}_{\text {stp }} \min ^{-1}$ and using sampling bags with a larger size than the current $2.58 \mathrm{~L}$. It will be mostly practical to increase the size of the sampling bag because this does not add significant weight or power consumption. An alternative more powerful pump could potentially increase the sample size, especially for the samples from high altitudes; however, it would also likely add more weight and consume more power that in turn increases the weight due to the need for more batteries.
Alternatively, to increase the amount of sample retrieved during one flight, additional bags can be considered. Currently the system is idle during several stages of the ascent as can be inferred from Fig. 5. This will however be more demanding on battery power. Furthermore, care has to be taken to avoid overlapping sampling schemes; i.e. sampling of a sample at altitude P1 is still ongoing while the set-point altitude for sample two, P2, is reached. This is complicated further with variable ascent speed, which is typical for these balloon flights.

\subsection{Uncertainty in sample amount and vertical resolution}

The accuracy in sounding of the Vaisala RS92-SGP pressure sensors is $1 \mathrm{hPa}$ respectively at $200 \mathrm{hPa}$, and $0.6 \mathrm{hPa}$ in the range 3-100 hPa (Vaisala, 2013). The uncertainty of RS92SGP pressure altitude is discussed in detail by Dirksen et al. (2014). The uncertainty of the vertical position of the RS92SGP radiosonde is $20 \mathrm{~m}$ and hence is also the uncertainty of the pressure-weighted mean altitude. Since the vertical resolution is calculated as the altitude where sampling stops minus the altitude at which sampling starts, the uncertainty in vertical resolution of the sampler is $29 \mathrm{~m}$, calculated using Gaussian error propagation.

The uncertainty in the estimated sample amount is a result of the uncertainty in pressure and temperature measurements. The pressure sensor in the manifold has an uncertainty of $2.6 \mathrm{hPa}$ (Honeywell, 2018) whereas the radiosonde temperature measurements have a $1 \sigma$ uncertainty of $0.25 \mathrm{~K}$ in sounding (Vaisala, 2013). This results in an error in estimated sample amount of $7.6 \mathrm{~mL}_{\mathrm{stp}}$.

Since the manifold pressure was not logged during the flight on 26 April, the pressure-weighted mean altitude of the samples had to be estimated using Eqs. (2) and (3). As mentioned earlier, Eq. (3) assumes a constant upstream pres- 
Table 7. Expected bias in stable isotope measurements on samples obtained by LISA, due to the limited accuracy of the LISA sampler. Typical values for the troposphere and stratosphere are taken from the indicated references: (A) Trolier et al. (1996); (B) Mrozek et al. (2016); (C) Nisbet et al. (2016); (D) Bergamaschi et al. (2001); (E) Aoki et al. (2003) and (F) Röckmann et al. (2011). Reported measurement reproducibility, Re, for stratospheric air is also provided. $\delta^{13} \mathrm{C}$ and $\delta^{18} \mathrm{O}$ values are with respect to Vienna Pee Dee Belemnite (VPDB) and $\Delta^{17} \mathrm{O}$ and $\delta^{2} \mathrm{H}$ are with respect to Vienna Standard Mean Ocean Water (VSMOW). $f_{\mathrm{c}}$ was calculated using a source value $395 \mathrm{ppm}\left(\mathrm{CO}_{2}\right)$ and $500 \mathrm{ppb}\left(\mathrm{CH}_{4}\right)$, and contamination mole fraction of $405 \mathrm{ppm}\left(\mathrm{CO}_{2}\right)$ and $1800 \mathrm{ppb}\left(\mathrm{CH}_{4}\right)$. For $f_{\mathrm{c} 1}$ contamination values of $0.84 \mathrm{ppm}$ $\left(\mathrm{CO}_{2}\right)$ and $1.8 \mathrm{ppb}\left(\mathrm{CH}_{4}\right)$ based on LISA AirCore observed mean bias, resulting in $\Delta \delta_{1}$. For $f_{\mathrm{c} 2}$ the maximum observed drift (Fig. 2) of $0.11 \mathrm{ppm}\left(\mathrm{CO}_{2}\right)$ and $2\left(\mathrm{CH}_{4}\right)$ are used, resulting in $\Delta \delta_{2}$.

\begin{tabular}{|c|c|c|c|c|c|c|c|}
\hline \multirow[b]{2}{*}{ Species } & \multirow[b]{2}{*}{$\delta_{\mathrm{c}} \% o$} & \multirow[b]{2}{*}{$\delta_{\mathrm{s}} \% 0$} & \multirow[b]{2}{*}{$\operatorname{Re} \%$} & \multicolumn{2}{|c|}{ LISA-AirCore } & \multicolumn{2}{|c|}{ Storage drift } \\
\hline & & & & $f_{\mathrm{c} 1}$ & $\left|\Delta \delta_{1}\right| \% o$ & $f_{\mathrm{c} 2}$ & $\left|\Delta \delta_{2}\right| \%$ \\
\hline$\delta^{13} \mathrm{C}\left(\mathrm{CO}_{2}\right)$ & $-7.5(\mathrm{~A})$ & $-8.4(\mathrm{E})$ & $0.02(\mathrm{E})$ & & 0.08 & & 0.01 \\
\hline$\delta^{18} \mathrm{O}\left(\mathrm{CO}_{2}\right)$ & $-2(\mathrm{~A})$ & $12(\mathrm{E})$ & $0.05(\mathrm{E})$ & 0.084 & 1.18 & 0.011 & 0.15 \\
\hline$\Delta^{17} \mathrm{O}\left(\mathrm{CO}_{2}\right)$ & $0(\mathrm{~B})$ & $7(\mathrm{~B})$ & $0.2(\mathrm{~B})$ & & 0.59 & & 0.08 \\
\hline$\delta^{13} \mathrm{C}\left(\mathrm{CH}_{4}\right)$ & $-47(\mathrm{C})$ & $-20(\mathrm{~F})$ & $0.7(\mathrm{~F})$ & & 0.04 & & 0.04 \\
\hline$\delta^{2} \mathrm{H}\left(\mathrm{CH}_{4}\right)$ & -85 (D) & $190(\mathrm{~F})$ & $2.3(\mathrm{~F})$ & 0.0014 & 0.38 & 0.0015 & 0.42 \\
\hline
\end{tabular}

sure, which is not the case during flight where the pressure decreases. This results in errors in both the estimated sample amount and the estimated sampling altitude. The error in the fit parameters is included in the calculation. The error in $p_{b}$ can be calculated using the uncertainties of the fit (Eq. 3) and the pressure and measurements can be calculated using standard error propagation. The error in sounding of the pressure sensors is $1 \mathrm{hPa}$ at $200 \mathrm{hPa}$ (Vaisala, 2013). The total uncertainty after $200 \mathrm{~s}$ of sampling is $9 \mathrm{~mL}_{\mathrm{stp}}$, slightly higher than the effect found above.

\subsection{Uncertainty of potential isotopic composition measurements}

The stratospheric air samples can be used for analysis of isotopic composition measurements of trace gases. Here we take $\mathrm{CO}_{2}$ and $\mathrm{CH}_{4}$ as an example to estimate the uncertainties of isotopic composition measurements due to the storage bias (see Table 3) or the LISA-AirCore bias (see Table 5), and the estimated isotopic signatures associated with the assumed contamination source.

The measured mole fraction $\left(C_{\mathrm{m}}\right)$ is the sum of the mole fraction of the original stratospheric air sample $\left(C_{\mathrm{s}}\right)$ and that of the contaminated air sample $\left(C_{\mathrm{c}}\right)$ in the bag, weighted with their respective contributions:

$C_{\mathrm{m}}=f_{\mathrm{s}} C_{\mathrm{s}}+f_{\mathrm{c}} C_{\mathrm{c}}$,

with $f_{\mathrm{c}}+f_{\mathrm{s}}=1$ and solving for $f_{\mathrm{c}}$ yields,

$f_{\mathrm{c}}=\frac{C_{\mathrm{m}}-C_{\mathrm{s}}}{C_{\mathrm{c}}-C_{\mathrm{s}}}=\frac{\text { bias }}{C_{\mathrm{c}}-C_{\mathrm{s}}}$,

given that the $C_{\mathrm{m}}-C_{\mathrm{s}}$ is the observed bias. The isotope composition after the mixing of the tropospheric contamination into the sample air, can be approximated with

$\delta_{m} \approx \delta_{\mathrm{s}} f_{\mathrm{s}}+\delta_{\mathrm{c}} f_{\mathrm{c}}$, where $\delta_{m}$ is the final isotopic composition, and $\delta_{\mathrm{s}}$ and $\delta_{\mathrm{c}}$ represent the isotope composition of source and contamination and $f_{\mathrm{s}}$ and $f_{\mathrm{c}}$ are the fractional contributions to the total number of molecules after mixing. We further define the bias of the isotopic composition measurement as follows:

$\Delta \delta=\delta_{m}-\delta_{\mathrm{s}}$

Combining Eqs. (8) and (9), and using $f_{\mathrm{c}}+f_{\mathrm{s}}=1$ again, we derive

$\Delta \delta=\left(\delta_{\mathrm{c}}-\delta_{\mathrm{s}}\right) f_{\mathrm{c}}$

For the calculation, we regard the mean differences between AirCore and LISA measurements (Table 5, e.g. 0.84 ppm for $\mathrm{CO}_{2}$ and $1.8 \mathrm{ppb}$ for $\mathrm{CH}_{4}$ ) as the upper limit of bias induced in the stratospheric samples. Another estimate is performed based on the storage test results that showed maximum drifts of $0.11 \mathrm{ppm}$ for $\mathrm{CO}_{2}$ and $2 \mathrm{ppb}$ for $\mathrm{CH}_{4}$, presented in Table 3.

The fraction $f_{\mathrm{c}}$ can be calculated according to Eq. (7) with $C_{\mathrm{s}}$ being the typical stratospheric mole fraction, which is taken to be $395 \mathrm{ppm}$ for $\mathrm{CO}_{2}$ and $500 \mathrm{ppb}$ for $\mathrm{CH}_{4}$. For the contaminated air, we use typical tropospheric values of $405 \mathrm{ppm}$ for the $\mathrm{CO}_{2}$ mole fraction and $1800 \mathrm{ppb}$ for the $\mathrm{CH}_{4}$ mole fraction. The isotopic compositions $\delta_{\mathrm{c}}$ and $\delta_{\mathrm{s}}$ are taken from various references, and are presented in Table 7 .

We can readily see that the estimated biases due to the storage are relatively small compared to the typical analytical precisions, also presented in Table 7. The estimated biases in stable isotope measurements based on the observed differences between AirCore and LISA may be significant in certain cases, but should be considered an upper estimate, since these are based on maximum differences between the troposphere-stratosphere mole fractions and isotopic composition. Hence the LISA sampler provides a viable sampling tool for useful measurements of stable isotopes in $\mathrm{CO}_{2}$ and $\mathrm{CH}_{4}$. 


\section{Conclusions}

We have developed a new lightweight stratospheric air sampler, named LISA. The LISA sampler weighs $\sim 2.5 \mathrm{~kg}$, and is designed to collect four bag samples in the stratosphere during a balloon flight for $\mathrm{CO}_{2}, \mathrm{CH}_{4}$ and $\mathrm{CO}$ mole fraction measurements. Laboratory test results show that both MLF and Tedlar bags can maintain the sample mole fractions of $\mathrm{CO}_{2}$ and $\mathrm{CH}_{4}$ reasonably well for at least $4 \mathrm{~h}$; however, we choose the MLF bag because it outperforms the Tedlar bag in the stability of both $\mathrm{CO}$ and water vapour. Accounting for the storage drift and analysis uncertainty, we estimate the uncertainty of the LISA sample measurements to be $0.14 \mathrm{ppm}$ for $\mathrm{CO}_{2}, 2.3 \mathrm{ppb}$ for $\mathrm{CH}_{4}$ and $7.8 \mathrm{ppb}$ for $\mathrm{CO}$, respectively.

To assist the choice of the sampling strategy in terms of the sample vertical resolution and the sample size, we have evaluated the performance of the sampling pump in a pressurecontrolled environment. Based on the test results, we have estimated the expected sample size for each altitude and for each sampling time and found that the increase of the sample size is saturated around $200 \mathrm{~s}$ of sampling. A further increase of the sampling time would collect little additional air sample but decrease the vertical resolution.

The LISA sampler was successfully flown four times during balloon flights in Sodankylä, Finland, in April and September 2017, retrieving a total of 15 samples. The sample size ranges between 800 to $180 \mathrm{~mL}$ for the altitude between 12 and $25 \mathrm{~km}$, with the corresponding vertical resolution ranging from 0.5 to $1.5 \mathrm{~km}$. The collected air samples were analysed for $\mathrm{CO}_{2}, \mathrm{CH}_{4}$ and $\mathrm{CO}$ mole fractions, and evaluated against AirCore retrieved profiles, showing mean differences of to $0.84 \mathrm{ppm}$ for $\mathrm{CO}_{2}, 1.8 \mathrm{ppb}$ for $\mathrm{CH}_{4}$ and $6.3 \mathrm{ppb}$ for $\mathrm{CO}$, respectively.

The LISA sampler is thus a viable low-cost tool for retrieving stratospheric air samples, providing a complementary method to AirCore. Furthermore, The LISA sampler is advantageous for performing routine stratospheric measurements of isotopic compositions of trace gases.

Data availability. The data presented here are available on request. (huilin.chen@rug.nl)

Author contributions. JJDH, MdV, HAB, and $\mathrm{HC}$ designed and tested the sampler. The fieldwork in Sodankylä was performed by JJDH, MdV, PH, RK, and HC. The manuscript was prepared by $\mathrm{JJDH}$ and $\mathrm{HC}$ with contributions from all co-authors.

Competing interests. The authors declare that they have no conflict of interest.

Special issue statement. This article is part of the special issue "The 10th International Carbon Dioxide Conference (ICDC10) and the 19th WMO/IAEA Meeting on Carbon Dioxide, other Greenhouse Gases and Related Measurement Techniques (GGMT-2017) (AMT/ACP/BG/CP/ESD inter-journal SI)". It is a result of the 19th WMO/IAEA Meeting on Carbon Dioxide, Other Greenhouse Gases, and Related Measurement Techniques (GGMT-2017), Empa Dübendorf, Switzerland, 27-31 August 2017.

Acknowledgements. The authors thankfully acknowledge the help of Bert Kers, Truls Andersen and Marc Bleeker for their help during the laboratory tests. Juha Karhu (FMI) helped with balloon launching and payload recovery, which is highly appreciated. We like to thank Juha Hatakka (FMI) for maintaining the calibration gases in Finland. This research was (in part) funded by a grant (reference no. ALW-GO/15-10) from the User Support Programme Space Research. The presented AirCore flights were supported by ESA project FRM4GHG. We also acknowledge funding by the EU project RINGO, EU project GAIA-CLIM and Finnish Academy grant no. 140408 .

Edited by: Markus Leuenberger

Reviewed by: two anonymous referees

\section{References}

Aoki, S., Nakazawa, T., Machida, T., Sugawara, S., Morimoto, S., Hashida, G., Yamanouchi, T., Kawamura, K., and Honda, H.: Carbon dioxide variations in the stratosphere over Japan, Scandinavia and Antarctica, Tellus B, 55, 178-186, https://doi.org/10.1034/j.1600-0889.2003.00059.x, 2003.

Baldwin, M. P., Dameris, M., and Shepherd, T. G.: How will the stratosphere affect climate change?, Science 80, 1576-1577, https://doi.org/10.1126/science.1144303, 2007.

Beghi, S. and Guillot, J. M.: Sample water removal method in volatile organic compound analysis based on diffusion through poly(vinyl fluoride) film, J. Chromatogr. A, 1127, 1-5, https://doi.org/10.1016/j.chroma.2006.05.102, 2006.

Bergamaschi, P., Lowe, D. C., Manning, M. R., Moss, R., Bromley, T., and Clarkson, T. S.: Transects of atmospheric $\mathrm{CO}, \mathrm{CH}_{4}$, and their isotopic composition across the Pacific: Shipboard measurements and validation of inverse models, J. Geophys. Res.-Atmos., 106, 7993-8011, https://doi.org/10.1029/2000JD900576, 2001.

Butchart, N.: The Brewer-Dobson circulation, Rev. Geophys., 52, 157-184, https://doi.org/10.1002/2013RG000448, 2014.

Cariou, S. and Guillot, J. M.: Double-layer Tedlar bags: A means to limit humidity evolution of air samples and to dry humid air samples, Anal. Bioanal. Chem., 384, 468-474, https://doi.org/10.1007/s00216-005-0177-4, 2006.

Chen, H., Karion, A., Rella, C. W., Winderlich, J., Gerbig, C., Filges, A., Newberger, T., Sweeney, C., and Tans, P. P.: Accurate measurements of carbon monoxide in humid air using the cavity ring-down spectroscopy (CRDS) technique, Atmos. Meas. Tech., 6, 1031-1040, https://doi.org/10.5194/amt-6-1031-2013, 2013.

Chen, H., Kivi, R., Heikkinen, P., Kers, B., de Vries, M., Hatakka, J., Laurila, T., Sweeney, C., and Tans, P.: High-latitude balloon observations of $\mathrm{CO}_{2} / \mathrm{CH}_{4} / \mathrm{CO}$ using AirCore: evaluation of Sodankylä TCCON retrievals, in preparation, 2018. 
Crevoisier, C., Nobileau, D., Armante, R., Crépeau, L., Machida, T., Sawa, Y., Matsueda, H., Schuck, T., Thonat, T., Pernin, J., Scott, N. A., and Chédin, A.: The 2007-2011 evolution of tropical methane in the mid-troposphere as seen from space by MetOp-A/IASI, Atmos. Chem. Phys., 13, 4279-4289, https://doi.org/10.5194/acp-13-4279-2013, 2013.

Daube, J. C., Boering, K. A., Andrews, A. E., and Wofsy, S. C.: A high-precision fast-response airborne $\mathrm{CO}_{2}$ analyzer for in situ sampling from the surface to the middle stratosphere, J. Atmos. Ocean. Tech., 19, 1532-1543, https://doi.org/10.1175/15200426(2002)019<1532:AHPFRA>2.0.CO;2, 2002.

Dirksen, R. J., Sommer, M., Immler, F. J., Hurst, D. F., Kivi, R., and Vömel, H.: Reference quality upper-air measurements: GRUAN data processing for the Vaisala RS92 radiosonde, Atmos. Meas. Tech., 7, 4463-4490, https://doi.org/10.5194/amt-7-4463-2014, 2014.

Ehhalt, D. H., Röth, E. P., and Schmidt, U.: On the temporal variance of stratospheric trace gas concentrations, J. Atmos. Chem., 1, 27-51, https://doi.org/10.1007/BF00113978, 1983.

Engel, A., Strunk, M., Müller, M., Haase, H.-P., Poss, C., Levin, I., and Schmidt, U.: Temporal development of total chlorine in the high-latitude stratosphere based on reference distributions of mean age derived from $\mathrm{CO}_{2}$ and $\mathrm{SF}_{6}$, J. Geophys. Res., 107, 4136, https://doi.org/10.1029/2001JD000584, 2002.

Engel, A., Möbius, T., Bönisch, H., Schmidt, U., Heinz, R., Levin, I., Atlas, E., Aoki, S., Nakazawa, T., Sugawara, S., Moore, F., Hurst, D., Elkins, J., Schauffler, S., Andrews, A., and Boering, K.: Age of stratospheric air unchanged within uncertainties over the past 30 years, Nat. Geosci., 2, 28-31, https://doi.org/10.1038/ngeo388, 2009.

Engel, A., Bönisch, H., Schwarzenberger, T., Haase, H.-P., Grunow, K., Abalichin, J., and Sala, S.: Long-term validation of ESA operational retrieval (version 6.0) of MIPAS Envisat vertical profiles of methane, nitrous oxide, CFC11, and CFC12 using balloon-borne observations and trajectory matching, Atmos. Meas. Tech., 9, 1051-1062, https://doi.org/10.5194/amt-9-10512016, 2016.

Engel, A., Bönisch, H., Ullrich, M., Sitals, R., Membrive, O., Danis, F., and Crevoisier, C.: Mean age of stratospheric air derived from AirCore observations, Atmos. Chem. Phys., 17, 68256838, https://doi.org/10.5194/acp-17-6825-2017, 2017.

Fabian, P.: Atmospheric sampling, Adv. Space Res., 1, 17-27, https://doi.org/10.1016/0273-1177(81)90444-0, 1981.

Frankenberg, C., Aben, I., Bergamaschi, P., Dlugokencky, E. J., Van Hees, R., Houweling, S., Van Der Meer, P., Snel, R., and Tol, P.: Global column-averaged methane mixing ratios from 2003 to 2009 as derived from SCIAMACHY: Trends and variability, J. Geophys. Res.-Atmos., 116, D04302, https://doi.org/10.1029/2010JD014849, 2011.

Fuke, H., Iijima, I., Izutsu, N., Matsuzaka, Y., Kato, Y., Kakehashi, Y., Shoji, Y., Yoshida, T., Honda, H., Aoki, S., Inai, Y., and Morimoto, S.: Balloon launch and flight operation from the research vessel Hakuho Maru for stratospheric air sampling over the Eastern Pacific Equator, J. Atmos. Ocean. Tech., 31, 1540 1548, https://doi.org/10.1175/JTECH-D-13-00248.1, 2014.

Gerber, E. P., Butler, A., Calvo, N., Charlton-Perez, A., Giorgetta, M., Manzini, E., Perlwitz, J., Polvani, L. M., Sassi, F., Scaife, A. A., Shaw, T. A., Son, S. W., and Watanabe, S.: Assessing and understanding the impact of stratospheric dynamics and variabil- ity on the earth system, B. Am. Meteorol. Soc., 93, 845-859, https://doi.org/10.1175/BAMS-D-11-00145.1, 2012.

Greatwood, C., Richardson, T. S., Freer, J., Thomas, R. M., Rob Mackenzie, A., Brownlow, R., Lowry, D., Fisher, R. E., and Nisbet, E. G.: Atmospheric sampling on ascension island using multirotor UAVs, Sensors (Switzerland), 17, 1189, https://doi.org/10.3390/s17061189, 2017.

Holton, J. R., Haynes, P. H., McIntyre, M. E., Douglass, A. R., Rood, R. B., and Pfister, L.: Stratospheretroposphere exchange, Rev. Geophys., 33, 403-439, https://doi.org/10.1029/95RG02097, 1995.

Honda, H.: Development of stratospheric whole air sampling system using LHe as a cryogen and its operation results for 15 years, Adv. Space Res., 33, 1797-1805, https://doi.org/10.1016/j.asr.2003.08.029, 2004.

Honeywell: HSCMAND015PASA5,

available at: https://sensing.honeywell.com/ hscmand015pasa5-amplified-board-mount-pressure-sensors, last access: 19 January 2018.

Kaiser, J., Engel, A., Borchers, R., and Röckmann, T.: Probing stratospheric transport and chemistry with new balloon and aircraft observations of the meridional and vertical $\mathrm{N}_{2} \mathrm{O}$ isotope distribution, Atmos. Chem. Phys., 6, 3535-3556, https://doi.org/10.5194/acp-6-3535-2006, 2006.

Karion, A., Sweeney, C., Tans, P., and Newberger, T.: AirCore: An innovative atmospheric sampling system, J. Atmos. Ocean. Tech., 27, 1839-1853, https://doi.org/10.1175/2010JTECHA1448.1, 2010.

Kivi, R. and Heikkinen, P.: Fourier transform spectrometer measurements of column $\mathrm{CO}_{2}$ at Sodankylä, Finland, Geosci Instrum. Meth., 5, 271-279, https://doi.org/10.5194/gi-5-2712016, 2016.

Laube, J. C., Engel, A., Bönisch, H., Möbius, T., Sturges, W. T., Braß, M., and Röckmann, T.: Fractional release factors of long-lived halogenated organic compounds in the tropical stratosphere, Atmos. Chem. Phys., 10, 1093-1103, https://doi.org/10.5194/acp-10-1093-2010, 2010.

Lueb, R. A., Ehhalt, D. H., and Heidt, L. E.: Balloon-borne low temperature air sampler, Rev. Sci. Instrum., 46, 702-705, https://doi.org/10.1063/1.1134292, 1975.

Membrive, O., Crevoisier, C., Sweeney, C., Danis, F., Hertzog, A., Engel, A., Bönisch, H., and Picon, L.: AirCore-HR: a highresolution column sampling to enhance the vertical description of $\mathrm{CH}_{4}$ and $\mathrm{CO}_{2}$, Atmos. Meas. Tech., 10, 2163-2181, https://doi.org/10.5194/amt-10-2163-2017, 2017.

Morimoto, S., Yamanouchi, T., Honda, H., Aoki, S., Nakazawa, T., Sugawara, S., Ishidoya, S., Iijima, I., and Yoshida, T.: A new compact cryogenic air sampler and its application in stratospheric greenhouse gas observation at syowa station, Antarctica, J. Atmos. Ocean. Tech., 26, 2182-2191, https://doi.org/10.1175/2009JTECHA1283.1, 2009.

Mrozek, D. J., van der Veen, C., Hofmann, M. E. G., Chen, H., Kivi, R., Heikkinen, P., and Röckmann, T.: Stratospheric Air Subsampler (SAS) and its application to analysis of $\Delta^{17} \mathrm{O}\left(\mathrm{CO}_{2}\right)$ from small air samples collected with an AirCore, Atmos. Meas. Tech., 9, 5607-5620, https://doi.org/10.5194/amt-9-5607-2016, 2016.

Nakazawa, T., Machida, T., Sugawara, S., Murayama, S., Morimoto, S., Hashida, G., Honda, H., and Itoh, T.: Measurements 
of the stratospheric carbon dioxide concentration over Japan using a Balloon-borne cryogenic sampler, Geophys. Res. Lett., 22, 1229-1232, https://doi.org/10.1029/95GL01188, 1995.

Nakazawa, T., Aoki, S., Kawamura, K., Saeki, T., Sugawara, S., Honda, H., Hashida, G., Morimoto, S., Yoshida, N., Toyoda, S., Makide, Y., and Shirai, T.: Variations of stratospheric trace gases measured using a balloon-borne cryogenic sampler, Adv. Space Res., 30, 1349-1357, https://doi.org/10.1016/S02731177(02)00551-3, 2002.

Nisbet, E. G., Dlugokencky, E. J., Manning, M. R., Lowry, D., Fisher, R. E., France, J. L., Michel, S. E., Miller, J. B., White, J. W., Vaughn, B., Bousquet, P., Pyle, J. A., Warwick, N. J., Cain, M., Brownlow, R., Zazzeri, G., Lanoisellé, M., Manning, A. C., Gloor, E., Worthy, D. E., Brunke, E. G., Labuschagne, C., Wolff, E. W., and Ganesan, A. L.: Rising atmospheric methane: 2007-2014 growth and isotopic shift, Global Biogeochem. Cy., 30, 1356-1370, https://doi.org/10.1002/2016GB005406, 2016.

Paul, D., Chen, H., Been, H. A., Kivi, R., and Meijer, H. A. J.: Radiocarbon analysis of stratospheric $\mathrm{CO}_{2}$ retrieved from AirCore sampling, Atmos. Meas. Tech., 9, 4997-5006, https://doi.org/10.5194/amt-9-4997-2016, 2016.

Plumb, R. A.: Stratospheric Transport, J. Meteorol. Soc. Japan. Ser. II, 80, 793-809, https://doi.org/10.2151/jmsj.80.793, 2002.

Plumb, R. A.: Tracer interrelationships in the stratosphere, Rev. Geophys., 45, 1-33, https://doi.org/10.1029/2005RG000179, 2007.

Rella, C. W., Chen, H., Andrews, A. E., Filges, A., Gerbig, C., Hatakka, J., Karion, A., Miles, N. L., Richardson, S. J., Steinbacher, M., Sweeney, C., Wastine, B., and Zellweger, C.: High accuracy measurements of dry mole fractions of carbon dioxide and methane in humid air, Atmos. Meas. Tech., 6, 837-860, https://doi.org/10.5194/amt-6-837-2013, 2013.
Rice, A. L., Tyler, S. C., McCarthy, M. C., Boering, K. A., and Atlas, E.: Carbon and hydrogen isotopic compositions of stratospheric methane: 1. High-precision observations from the NASA ER-2 aircraft, J. Geophys. Res., 108, 4460, https://doi.org/10.1029/2002JD003042, 2003.

Röckmann, T., Brass, M., Borchers, R., and Engel, A.: The isotopic composition of methane in the stratosphere: high-altitude balloon sample measurements, Atmos. Chem. Phys., 11, 13287-13304, https://doi.org/10.5194/acp-11-13287-2011, 2011.

Schmidt, U., Kulessa, G., Klein, E., Röth, E. P., Fabian, P., and Borchers, R.: Intercomparison of balloon-borne cryogenic whole air samplers during the MAP/GLOBUS 1983 campaign, Planet. Space Sci., 35, 647-656, https://doi.org/10.1016/00320633(87)90131-0, 1987.

Sugawara, S., Nakazawa, T., Shirakawa, Y., Kawamura, K., Aoki, S., Machida, T., and Honda, H.: Vertical profile of the carbon isotopic ratio of stratospheric methane over Japan, Geophys. Res. Lett., 24, 2989-2992, https://doi.org/10.1029/97GL03044, 1997.

Trolier, M., White, J. W. C., Tans, P. P., Masarie, K. A., and Gemery, P. A.: Monitoring the isotopic composition of atmospheric $\mathrm{CO}_{2}$ : Measurements from the NOAA Global Air Sampling Network, J. Geophys. Res.-Atmos., 101, 25897-25916, https://doi.org/10.1029/96JD02363, 1996.

Vaisala: Vaisala radiosonde RS92, available at: https://www.vaisala. com/en (last access: 19 January 2018), 2013.

Wunch, D., Toon, G. C., Blavier, J. F. L., Washenfelder, R. A., Notholt, J., Connor, B. J., Griffith, D. W., Sherlock, V., and Wennberg, P. O.: The total carbon column observing network, Philos. T. Roy. Soc. A, 369, 2087-2112, https://doi.org/10.1098/rsta.2010.0240, 2011. 